\title{
Measurement theory in linguistics
}

\author{
Galit Weidman Sassoon
}

Received: 1 June 2009 / Accepted: 3 October 2009 / Published online: 27 October 2009

(C) The Author(s) 2009. This article is published with open access at Springerlink.com

\begin{abstract}
This paper presents a novel semantic analysis of unit names (like pound and meter) and gradable adjectives (like tall, short and happy), inspired by measurement theory (Krantz et al. In Foundations of measurement: Additive and Polynomial Representations, 1971). Based on measurement theory's four-way typology of measures, I claim that different adjectives are associated with different types of measures whose special characteristics, together with features of the relations denoted by unit names, explain the puzzling limited distribution of measure phrases, as well as unitbased comparisons between predicates (as in the table is longer than it is wide). All considered, my analyses support the view that the grammar of natural languages is sensitive to features of measurement theory.
\end{abstract}

Keywords Unit · Measure phrase - Measurement theory · Degree ·

Gradable adjective

\section{Introduction: measurement theory in grammar}

\subsection{The aims and structure of this paper}

Measures can be described as mappings of individuals to degrees along dimensions (height, width, loudness, etc.; cf., Krantz et al. 1971). My main claim in this paper is that the grammar of natural language is sensitive to the distinctions of measurement

\footnotetext{
G. Weidman Sassoon $(\varangle)$

ILLC, University of Amsterdam, Science Park 904, 1098 XH, Amsterdam,

The Netherlands

e-mail: galitadar@gmail.com

G. Weidman Sassoon

Ben Gurion University, Beer Sheva, Israel
} 
theory's taxonomy of measure types. This four-level taxonomy goes back to Stevens (1946, 1975), who dubbed the by now widely used names for the four measure typesratio-scale measures (also known as extensive measures), interval-scale, ordinal-scale and nominal-scale measures. Measurement theory was not only found useful in the analysis of the correct use of measurement in natural sciences such as physics, but also in other sciences. In particular, its taxonomy is extensively used in statistics and its application for research methods in the social sciences (Babbie 2004). It is also an important source of influence in the field of psychophysics, where it is found useful in describing the way subjects perceive and represent scalar properties of stimuli (Anderson 1996), ranging from properties such as sound, color, and weight to scales of, for instance, pain, well-being and even grammaticality judgments (Featherstone to appear).

In order to demonstrate that grammar is sensitive to measurement theory's distinctions, in this paper I address problems pertaining to the interpretation and distribution of unit names, like pound and meter, that form measure phrases (as in two pounds). Measure phrases occur in constructions like two meters tall ('numerical degree predicates'), as well as two pounds of cheese ('classifier constructions'). I focus on the former structure, whose distribution is highly restricted. While linguists usually attempt to explain the puzzling distribution of measure phrases by inventing new semantic, syntactic or lexical constraints (cf., von Stechow 1984a; Kennedy 1999; Landman 2005; Schwarzschild 2005, 2006, etc.), I argue that these puzzles can be explained by using existing tools (e.g., measurement theory). In that sense, my proposal is, methodologically speaking, more economic or basic. More significantly, my proposal is radical in that it argues for a cognitive mechanism (module) which is a measurement system, containing a hierarchy of four measurement types, i.e. I argue that some distinctions of measurement theory embody axioms of natural logics, rather than general theories, where the former are distinguished from the latter in that a mature speaker is disposed to use them. Evidence for this is formed by grammaticality judgments that, I show, are sensitive to measurement types.

In part 1 , I present the relevant taxonomy of measurements and the facts I attempt to explain in its terms. In part 2, I present a new analysis of unit names and measure phrases (Sassoon 2007, Chap. 9), which is directly inspired by measurement theory (cf. Krantz et al. 1971; Klein 1980, 1991). In part 3, I explore the consequences of this analysis. I claim that different gradable predicates are associated with different types of measures. The special characteristics of these measure types, together with features of the relations denoted by unit names, explain the limited distribution of measure phrases. Additional advantages of the proposal are briefly explored. Part 4 presents a comparison with previous analyses. I show that these analyses are either too weak (fail to account for certain felicitous uses of measure phrases), or too strong (fail to predict the infelicity of measure phrases with many adjectives). In the present proposal, these problems are resolved.

\subsection{Measurement types in measurement theory}

Measurement theory offers the following four-level classification of scalar properties or degree functions (assignments of numbers to objects along a dimension; Stevens 
1946, 1975; Krantz et al. 1971; see also Wikipedia, the free Encyclopedia under 'Level of measurement').

The first level in the classification is called nominal. The only significance of nominal degree functions lies in the fact that entities are assigned the same or different values. If the values are numerals, the choice of numerals is irrelevant and the only comparisons to be made between variable values are equality and inequality. There are no "less than" or "greater than" relations among the values, nor operations such as addition or subtraction. An example is the set of eye colors (brown, blue, green, etc.), or the set of truth values $\{0,1\}$.

The second level is called ordinal. Here, the numbers assigned to objects represent their rank order (1st, 2nd, 3rd etc.) Comparisons of "greater than" and "less than" can be made, in addition to equality and inequality. But operations such as addition and subtraction are still meaningless. Examples include the results of a horse race or a swimming competition, which state only which competitors arrived first, second, third, etc. but do not state time intervals.

The third level is called interval, where, in addition to the features of an ordinal level, equal differences between values represent equivalent intervals. Thus, operations such as subtraction are meaningful. Yet, the zero point on the scale is arbitrary and negative values can be used. Thus, neither sums of nor ratios between numbers on the scale are meaningful, and operations such as multiplication, division and addition cannot be carried out directly (only ratios of differences between pairs of values can be expressed; one difference can be twice the other, etc. $)^{1}$ Examples are the year date in many calendars and temperature in the Celsius or Fahrenheit scale. The fact that the water freezing point is mapped to the $0^{\circ} \mathrm{C}$ is arbitrary (as arbitrary as the fact that the water boiling point is mapped to the $100^{\circ} \mathrm{C}$ ). The freezing point does not correspond to non-existence of temperature, in fact it corresponds to $273^{\circ} \mathrm{K}$. Accordingly, it is meaningless to say that $20^{\circ} \mathrm{C}$ is twice as hot as $10^{\circ} \mathrm{C}$, in the sense that $20^{\circ} \mathrm{C}$ does not represent a double amount of heat (for further discussion see Sect. 3.4).

The forth level is called ratio. Ratio functions have all the features of interval functions, in addition to meaningful ratios between values. Operations such as multiplication, division and addition are therefore meaningful. The zero value on a ratio scale is non-arbitrary. Most physical quantities, such as mass, length or energy are measured in ratio scales; so is temperature measured in Kelvin (that is, relative to absolute zero), age measures, etc.

Now let us see the data I attempt to explain in terms of these four levels of measurements.

\subsection{The distribution of unit names and measure phrases}

Not all measures are associated with established units. Conventional unit names are usually only associated with lexical entries whose interpretation is linked with measures of external physical quantities. Examples include adjectives such as tall,

\footnotetext{
1 This point may become clearer following the discussion in Sect. 3.3.
} 
wide, long, hot, fast and late, verbs like to weigh, and nominal forms like height, width and weight. Consequently, the distribution of measure phrases is highly restricted.

Furthermore, each unit name is intimately linked to a limited set of predicates, and more often than not, only to predicates whose interpretations represent measures of one and the same thing. For example, unit names like Kelvin and Celsius are only associated with predicates whose degree functions represent measures of heat (energy) or temperature, such as hot and warm (as in twenty degrees warmer), and unit names like minute or month are only associated with predicates whose degree functions represent temporal measures, such as long (in its temporal sense), old and late.

Other adjectival interpretations are linked to no conventional measuring systems at all, or only to systems used by a relatively small community of experts (doctors, electricians, statisticians, psychologists, etc.) These adjectives do not combine with unit names. Examples include adjectives like healthy, bright, likely, good, beautiful and happy.

Besides the limitations posed by the restricted distribution of unit names, the distribution of measure phrases is further restricted by other factors, pertaining to the type of adjective in question (Horn 1972; Seuren 1978; von Stechow 1984b; Bierwisch 1989; Kennedy 2001).

First, negative antonyms of adjectives with unit names, e.g., short, narrow and slow, cannot combine with measure phrases (in the so-called positive form), as demonstrated by the felicity of two meters tall and three weeks old in comparison with the infelicity of \#two meters short and \#two weeks young.

Second, many positive adjectives whose interpretation is straightforwardly linked to physical measures and unit names, nevertheless do not combine with measure phrases. This can be demonstrated by the infelicity of examples such as \#two degrees warm, \#two dollars expensive and \#two kilos heavy (Kennedy 2001; Schwarzschild 2005).

Furthermore, there is a considerable variation between languages as to the set of positive adjectives that admit measure phrases (Schwarzschild 2005; Moltmann 2006). For example, on the one hand, tall is thought of as the prime example of an adjective that combines with measure phrases, but its French equivalent does not [*grand de 1,27 meters, '1.27 m tall'; Schwarzschild, (2005)]. On the other hand, the German numerical degree constructions 100 Tonnen schwer ('one hundred tones heavy'), $35^{\circ}$ heiss ('35 degrees hot') and even $-10^{\circ}$ kalt (' -10 degrees cold') are perfectly felicitous, unlike the respective ill formed English translations (Schwarzschild 2005). In other languages (like Hebrew), measure phrases do not combine with adjectives, but they do combine with a restricted set of nominalizations, as in gova shney meter ('height two meter', 'height of two meters').

Finally, despite their narrow and puzzling distribution, measure phrases are productively construed and used. First, speakers creatively invent new measure phrases based on non-established units, as demonstrated by examples such as two heads taller, two fingers wide(r) and two aspirins sick(er) (I thank Louise McNally for this last example). Second, comparative constructions freely allow measure phrases with positive and negative adjectives, as is demonstrated by the felicity of two meters shorter, two month younger, 2 degrees warmer, and two dollars more expensive. This holds 
true across many languages and different comparative constructions. ${ }^{2}$ In fact, some languages never allow for measure phrases to directly combine with adjectives in the positive form, even though they do allow measure phrases in comparatives (examples include Japanese, Russian and Spanish); yet, we do not know of languages where the reverse pattern holds (Schwarzschild 2005).

The licensing of ratio modifiers like twice is related in intricate ways to that of measure phrases. While ratio modifiers are most acceptable and most often used with positive adjectives that license measure phrases (as in, for instance, Dan is twice as tall as Sam), negative adjectives in the positive form, combine neither with measure phrases, nor with ratio modifiers (as illustrated by the infelicity of examples such as \#Dan is twice as short as Sam. However, many positive adjectives (like happy), which resemble negative ones in not licensing measure phrases, are acceptable with twice, e.g., I am twice as happy as I used to be is not as bad as \#Dan is twice as short as Sam. This contrast is also attested by the fact that speakers use twice more often with happy than with short. In a study of Google-search results (Sassoon 2009), the proportion of ratio constructions (twice as Adj. as) out of the total amount of equative constructions (as Adj. as) is more than five times greater with happy (15\%) than with short ( $3 \%$ ). Averaging over 27 antonym pairs, all in all, this proportion is about four and a half times greater in positive adjectives than in their negative antonyms.

How, in a nutshell, do I attempt to deal with this data?

The present paper provides a general framework, within which different adjectives are systematically associated with different measure-types. The first crucial point in my proposal is that any gradable predicate (including, e.g., happy) is associated with a degree function (mapping of entities to numbers), but in no predicate is the degree function fully specified (including, e.g., tall!), which explains the distribution of unit names, measure phrases (in numerical degree constructions), and ratio-modifiers (as will be demonstrated shortly). In this proposal, even when predicates are associated with ratio-scale functions, they are associated with different functions in different indices (say, different worlds). While in some predicates, ratios and/or differences between degrees are preserved (they do not vary across different indices), in others, they do vary, thereby creating vagueness (as explained in Part 2 onwards).

My main purpose in this paper is to deal with adjectives whose functions encode degree ratios (e.g. tall). These adjectives license both ratio modifiers (as in three times as tall) and measure phrases (e.g., two meters tall). This fact directly relates to the second crucial point in my proposal. While semantic theories often treat the interpretation of unit names as basic or given, I attempt to specify its content. Most significantly, I claim that a unit-name's interpretation is mediated by the application of a ratio operation (e.g., meter is interpreted as equivalent to $\lambda \mathrm{P} \lambda \mathrm{n} \lambda \mathrm{x}$. $\mathrm{x}$ is $\mathrm{n}$ times as $\mathrm{P}$ as the meter, where $\mathrm{P}, \mathrm{n}$ and $\mathrm{x}$ are variables ranging over scalar properties, numbers and individuals, respectively). The mediating ratio operation directly constrains the types of adjectives

\footnotetext{
2 Note that although \#Dan is one meter short is odd, we can felicitously say things like Lyn died two month short of her 60th birthday. In this example, the adjective short licenses a measure phrase, as it functions as a comparative adjective, conveying that the time difference between Lyn's birthday and death is two months (cf. Murphy 2006; Schwarzschild 2008); same for early/late when interpreted with respect to some 'required time'.
} 
that license unit names, to just those adjectives whose degree functions appropriately encode ratios between entities' degrees. Thereby it constrains the distribution of measure phrases to ratio-scale adjectives (examples include certain positive adjectives and all comparative adjectives across languages).

My third point relates to a pretty common view whereby the interpretation of comparative morphemes is mediated by the application of a difference operation. ${ }^{3}$ If this view is on the right track, and measurement theory is linguistically relevant, it follows that morphologically-gradable adjectives in general [i.e., adjectives that freely combine with comparative morphemes, as in taller, healthier and happier; Kennedy (1999)] all belong to one of the two higher levels of measurement, i.e., ratio and interval scales, because only those levels appropriately encode degree differences. In Parts 3 and 4, I attempt to defend this view. On the one hand, I show that the association of many adjectives with interval-scale measures (which predicts their non-licensing with measure- and ratio-phrases) is motivated by intuitions that speakers have (or do not have) concerning their degree functions, their zero point, and so on. Examples include virtually all negative adjectives, as claimed in Sassoon (2009), but also many positive ones, as I claim here. On the other hand, I argue that many adjectives that are intuitively thought to be ordinal, like happy, can be interpreted as denoting ratio-scale measures. I specify four sources for cross linguistic variation in the felicity of measure phrases, three of which pertain to the non-licensing of measure phrases even by ratio-scale adjectives, i.e., adjectives that do combine with ratio modifiers (e.g., happy).

Finally, the present analysis of unit names allows for a novel analysis of comparisons between predicates that have a unit in common (as in the table is longer than it is wide). I explain the precise sense in which different measures can be said to have a common unit.

Having described the data, I can now present in detail my proposal (Part 2), its direct consequences (Part 3), and its broader implications (Part 4).

\section{My proposal}

\subsection{Vagueness pertaining to degrees}

My implementation of ideas from measurement theory in the semantics of adjectives is unique in that it crucially relies on observations regarding the information that different adjectival degree functions do or do not encode, i.e., the idea of vagueness as pertaining to degree constructions is central to the present analysis (cf., Sect. 1.3).

Following Stalnaker (1978), let us call the linguistic and world knowledge of a given community of speakers an actual context. In standard vagueness models (Kamp 1975; Fein 1975; Veltman 1984; Landman 1991), expressions are assigned interpretation relative to information states (contexts) $\mathrm{c}$. Let $\mathrm{M}_{\mathrm{C}}$ be a vagueness model for a domain $\mathrm{D}$ and a set of contexts $\mathrm{C}$. For any context $\mathrm{c} \in \mathrm{C}$, let $\mathrm{T}_{\mathrm{c}} \subseteq \mathrm{C}$ be the set of contexts of total information extending c (c's completions). In (and only in)

\footnotetext{
3 Cf. von Stechow (1984b), Schwarzschild and Wilkinson (2002), Kennedy and McNally (2005), Schwarzschild (2005), (Kennedy and Levin, 2007, p. 17), and Sassoon (2009). See also Part 4 below.
} 
contexts of total information (supervaluations; van Fraassen 1969) the truth value of all statements $\varphi$ is determined (it is either true or false). Let the set of statements that are true in c consist of the statements that are true in every completion $\mathrm{t} \in \mathrm{T}_{\mathrm{c}}$ of $\mathrm{c}$ ('super-true' in van Fraassen 1969) and the set of statements that are false in c consist of the statements that are false in every total extension t of c ('super-false')

(1) a. $\llbracket \varphi \rrbracket_{\mathrm{c}}=1$ iff $\forall \mathrm{t} \in \mathrm{T}_{\mathrm{c}}, \llbracket \varphi \rrbracket_{\mathrm{t}}=1$

b. $\llbracket \varphi \rrbracket_{\mathrm{c}}=0$ iff $\forall \mathrm{t} \in \mathrm{T}_{\mathrm{c}}, \llbracket \varphi \rrbracket_{\mathrm{t}}=0$

c. Otherwise, $\llbracket \varphi \rrbracket_{\mathrm{c}}$ is undetermined

Let $\mathrm{T}$ be the set of total contexts in $\mathrm{C}$. I associate adjectives with the following semantics:

(2) For any $t \in T$, and any gradable adjective $P$ :

a. Let $\mathrm{f}_{\mathrm{P}, \mathrm{t}} \in \mathfrak{R}^{D}$ be the degree function of $P$ in $t$ (a function from entities $\mathrm{d}$ in the domain of discourse $\mathrm{D}$ to real numbers $\mathrm{r}$ in $\Re$ )

b. Let $\mathrm{c}_{\mathrm{P}, \mathrm{t}} \in\{0,1\}^{D}$ be the characteristic function of $P$ in $t$ (where 1 and 0 stand for truth values).

c. $\mathrm{P}$ denotes either $\mathrm{f}_{\mathrm{P}, \mathrm{t}}$ or $\mathrm{c}_{\mathrm{P}, \mathrm{t}}$, depending on the linguistic context.

For instance, in statements like Dan is taller than Sam, the adjective tall denotes $\mathrm{f}_{\text {tall, } \mathrm{t}}$ (as I show in Sect. 3.1), while in statements like Dan is tall, tall (or its projection) denotes $\mathrm{c}_{\text {tall, }} \mathrm{t}^{5}$

While in standard vagueness models, supervaluations represent different cutoff points for vague adjectives like tall, in the present proposal, they serve to represent different possible mappings of entities to numbers. Some of these mappings correspond to existing measuring conventions. For example, while in a total context $t_{1}$ the

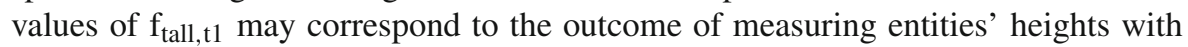
a centimeter ruler (so, e.g., the meter is mapped to the number 100), in another total context $t_{2}$ the values of $f_{\text {tall, } t 2}$ may correspond to the outcome of measuring entities' heights with an inch ruler (so, e.g., the meter is mapped to 39.4). The interpretation of tall does not comprise of one specific measuring system. ${ }^{6}$

We need a representation of vagueness pertaining to degrees, because some information is not encoded by adjectival degree functions. In particular, ordering dimensions (height, heat, happiness, etc.) are typically mass noun interpretations, although we cannot directly count quantities of the 'stuff' denoted by such nouns. No given quantity of water, height, heat or happiness is unequivocally associated with a given

\footnotetext{
${ }^{4}$ For example, the truth of a statement like it rains is considered common knowledge in a given context $\mathrm{c}$ iff it holds true in every completion $\mathrm{t}$ in $\mathrm{T}_{\mathrm{c}}$; the falsity of a statement is considered common knowledge in $c$ iff it is false (e.g., it does not rain) in every completion $t$ in $T_{c}$. The truth value is undetermined in $c$ iff $T_{c}$ includes both a completion in which it is true (e.g., it rains) and a completion in which it is false (it does not rain).

5 Thus, my analysis of the positive form Dan is tall differs from, e.g., Kennedy (1999) and Rett (2007) only in that I do not take a stand as to whether the characteristic function or the degree function is more basic or primitive [for the view that they simply constrain one another see Sassoon (2007); see also Krasikovsa (2009)].

${ }^{6}$ In the actual world we measure tallness in all kinds of ways. This fact is represented in my model too (I assign denotations to phrases like two centimeters and two inches in every index, regardless of the underlying $\mathrm{f}$.)
} 
(context-invariant) value like 1 or 2 or 345 . Thus, objects $d$ with a non-zero quantity of, e.g., height, should be mapped to different numbers in different total contexts in $\mathrm{T}_{\mathrm{c}}$ of an actual context $\mathrm{c}$.

(3) Context variant mapping to numbers: $\exists t_{1}, t_{2} \in T_{c}: f_{\text {tall, t1 }}(d) \neq f_{\text {tall, t2 }}(d)$.

In fact, many functions (types of rulers, if you like) adequately represent heights. Any function that maps equally tall entities to the same number and that maps the concatenation of $\mathrm{n}$ equally tall entities to $\mathrm{n}$ times that number, is additive with respect to height, i.e. adequately represents differences and ratios between entities' heights. For example, the mapping of two equally tall entities, $\mathrm{d}_{1}$ and $\mathrm{d}_{2}$, and their concatenation, $\mathrm{d}_{1} \bigoplus$ height $\mathrm{d}_{2}$, to the values 5,5 and 10 , respectively, is additive. But so is their mapping to 2, 2, and 4, respectively, and so is their mapping to 100, 100 and 200, respectively, etc. Each mapping corresponds to (the outcome of measuring entities' heights with) some possible ruler (inch, centimeter, meter, etc.) Notice, however, that, in the present proposal, these mappings form the interpretation of tall, not of unit names like inch. The interpretation of the latter is discussed next.

\subsection{Information about degree ratios and the interpretation of unit names}

We see that many different functions may be associated with adjectives like tall. Despite this intrinsic vagueness in the mapping of entities to degrees, some information is encoded by adjectival degree functions. In particular, all the functions that may be associated with tall adequately represent height ratios. This means that they share the same ratios between degrees. For example, since the height of $d_{1} \bigoplus$ height $d_{2}$ is twice the height of $d_{1}$ in all the examples just given, the ratio between their degrees is the number 2 in all these examples $(2 \times 5=10 ; 2 \times 2=4$ and $2 \times 100=200)$. In fact, all rulers specify the same ratios between entities' degrees (precisely the ratios between the entities' heights). As these ratios are easily accessible to us (they are unequivocally determined numbers, identical in all the additive measuring systems), in any $\mathrm{t}, \mathrm{f}_{\mathrm{tall}, \mathrm{t}}$ should adequately represent them. Thus:

(4) Context invariant ratios:

$\forall \mathrm{d} \in \mathrm{D}, \forall \mathrm{t} \in \mathrm{T}_{\mathrm{c}}$, entities with $\mathrm{n}$ times d's height are mapped to $\mathrm{n} \times \mathrm{f}_{\text {tall, } \mathrm{t}}(\mathrm{d})$.

For another example, consider an A4 sheet of paper. What is the number representing its length? Clearly, the answer depends on the ruler. While in inches its length is assigned the number 11.69, in centimeters it is 29.7, and by using any of an indefinite number of other possible additive measuring conventions, we may assign it any other number. Conversely, for any possible measuring system, the ratio between the lengths of an A4 and a 'letter' paper, is one and the same number, $1.413(=11.69 / 11=29.7 / 27.9=\ldots)$

All tall's functions in $\mathrm{T}_{\mathrm{c}}$, then, yield the same ratios between entities' degrees (these ratios are context-invariant numbers). ${ }^{7}$ The conclusion to be drawn from the above observations is the following. It is not the case that, say, Dan is 2 meters tall is true in

\footnotetext{
${ }^{7}$ Surely objects may shrink or expand in different temperatures; they may increase over time, etc. Thus, degree functions of adjectives like tall map entities to numbers per a given total context and time point, and
} 
a context $\mathrm{c}$ iff in every total context $\mathrm{t}$ of $\mathrm{T}_{\mathrm{c}}, \mathrm{f}_{\text {tall, } \mathrm{t}}$ maps Dan to 2 . In any actual context $\mathrm{c}$, the value to which $\mathrm{f}_{\text {tall, } \mathrm{t}}$ maps Dan varies across accessible total contexts, rendering Dan's value undetermined.

$$
\neg \exists \mathrm{n} \in \mathfrak{R}: \forall \mathrm{t} \in \mathrm{T}_{\mathrm{c}}, \mathrm{f}_{\mathrm{tall}, \mathrm{t}}\left(\left[\mathrm{Dan} \rrbracket_{\mathrm{t}}\right)=\mathrm{n} .\right.
$$

Rather, the truth of statements with numerical degree predicates must be determined based on height ratios. In particular, directly based on measurement theory (cf. Klein 1991), I propose that an entity d falls under the predicate 2 meters tall iff the ratio between d's degree in tall and the degree in tall of the original meter stick in Paris or any other entity that is $1 \mathrm{~m}$ tall ('a meter unit-object'), $\mathrm{r}_{\mathrm{m}, \mathrm{t}}$, is 2 :

(6) $\llbracket$ Dan is $2 \mathrm{~m}$ tall $\rrbracket_{\mathrm{c}}=1$ iff $\forall \mathrm{T} \in \mathrm{T}_{\mathrm{c}}: \mathrm{f}_{\text {tall,t } \mathrm{t}}\left(\llbracket\right.$ Dan $\left.\rrbracket_{\mathrm{t}}\right)=2 \times \mathrm{r}_{\mathrm{m}, \mathrm{t}}$.

In the next Section, I turn this suggestion into a formal analysis of unit names.

\subsection{An analysis of unit names}

Unit nouns (e.g., meter) are extensional in the sense of being directly linked to a set of entities which, by virtue of a convention, are regarded as unit objects, e.g., the entities whose height we call 'one meter'. This set, then, does not vary across the total contexts of any given actual context c. ${ }^{8}$

(7) Unit objects: For any unit name unit, let $\mathrm{D}_{\mathrm{u}} \subseteq \mathrm{D}$ be the set of unit objects of unit.

I adapt the view that the word meters in statements such as Dan is two meters tall is interpreted relationally (Krifka 1989; Chierchia 1998, p. 74). Directly based on measurement theory, I argue that it is interpreted as equivalent to the predicate " $\lambda \mathrm{P} . \lambda \mathrm{r} . \lambda \mathrm{x}$. $\mathrm{x}$ is $\mathrm{r}$ times as $\mathrm{P}$ as a meter unit-object". In this interpretation, in every total context $\mathrm{t}$, the unit name denotes (the Schonfinkelized function of) a relation between (the degree function of) an adjective $\mathrm{P}$ (e.g. tall, wide, long, etc.), a (real) number r, an and entity $\mathrm{d}$ in $\mathrm{D}$, such that d's amount of P-hood (e.g., d's height, represented numerically by the value $f_{\text {tall, } t}(d)$ ) equals $r$ times that of a meter unit-object (represented by the value $\mathrm{f}_{\text {tall, } t}\left(\mathrm{~d}_{\mathrm{m}}\right)$, for any meter unit object $\mathrm{d}_{\mathrm{m}} \in \mathrm{D}_{\mathrm{m}}$; Since all unit objects are equally tall, we can represent their degree as a constant, $\mathrm{r}_{\mathrm{m}, \mathrm{t}}$ ).

Hence, the semantic value of two meters tall is (the characteristic function of) the set $\left\{d \in D: f_{\text {tall, } t}(d)=2 \times \sigma\left(\left\{f_{\text {tall }, t}\left(d_{m}\right): d_{m} \in D_{m}\right\}\right)\right\}$ (where $\sigma$ is a function from singletons to their unique members), which reduces to the set $\left\{d \in D: f_{\text {tall, }}(d)=2 \times\right.$ $r_{m, t}$ \} (where $r_{m, t}$ is the real number $f_{\text {tall, } t}$ associates with the meter unit objects in $t$ ). The semantic value of 2 degrees Kelvin (hot) is $\left\{\mathrm{d} \in \mathrm{D}\right.$ : $\mathrm{f}_{\text {hot, }, t}(\mathrm{~d})=2 \times \sigma\left(\left\{\mathrm{f}_{\text {hot, }}\left(\mathrm{d}_{\mathrm{K}}\right)\right.\right.$ : $\left.\left.\left.\mathrm{d}_{\mathrm{K}} \in \mathrm{D}_{\mathrm{K}}\right\}\right)\right\}$, which reduces to $\left\{\mathrm{d} \in \mathrm{D}: \mathrm{f}_{\text {tall, } \mathrm{t}}(\mathrm{d})=2 \times \mathrm{r}_{\mathrm{K}, \mathrm{t}}\right\}$, etc. Thus, we can give a general interpretation rule for unit names and numerical degree predicates:

\section{Footnote 7 continued}

entities' height ratios are identical in every total context per a given time point. For simplicity, I omit time indices.

8 Probably unit nouns in classifier constructions can directly refer to the set of unit objects (as in several pounds of cheese; Schwarzschild 2005; Brasoveanu 2008). 
Table 1 An example of my proposal

\begin{tabular}{llll}
\hline & & &
\end{tabular}

(8) Let us add to the language the category UNIT $\subseteq \mathrm{NOUN}^{3}$ that consists of words like $\operatorname{meter}(s), \operatorname{gram}(s)$, etc.

$\forall \mathrm{t} \in \mathrm{T}, \forall \mathrm{P} \in \mathrm{ADJ}, \forall \mathrm{u} \in \mathrm{UNIT}$ such that $\mathrm{u}$ is a unit name of $\mathrm{P}$ :

(9) The unit objects' degree:

$\exists r_{u, P} \in \Re, r_{u, P} \neq 0: D_{u}=\left\{d \in D: f_{P, t}(d)=r_{u, P}\right\}$.

In any $t, f_{P, t}$ assigns all unit objects the same number, $r_{u, P}$.

(10) Unit names and numerical degree predicates

$\llbracket \lambda$ r. $\lambda x . u(P, r, x) \rrbracket_{t}=\lambda r \in \Re . \lambda d \in D$. for some $d_{u} \in D_{u}: f_{P, t}(d)=r \times f_{P, t}\left(d_{u}\right)$.

In any $\mathrm{t}$, the denotation of a numerical degree predicate that is based on $\mathrm{u}$ and $\mathrm{P}$ is a relation between numbers $r$ and objects $d$, such that d's degree in $P$ equals $r$ times the degree of any unit-object $\mathrm{d}_{\mathrm{u}}$.

For example, [centimeters $\rrbracket_{\mathrm{t}}=\lambda \mathrm{f}_{\mathrm{P}, \mathrm{t}} \in \mathfrak{R}^{D} . \lambda \mathrm{r} \in \Re . \lambda \mathrm{d} \in \mathrm{D}$. for some $\mathrm{d}_{\mathrm{cm}} \in \mathrm{D}_{\mathrm{cm}}$ : $\mathrm{f}_{\mathrm{P}, \mathrm{t}}(\mathrm{d})=\mathrm{r} \times \mathrm{f}_{\mathrm{P}, \mathrm{t}}\left(\mathrm{d}_{\mathrm{cm}}\right)$. Table 1 illustrates my proposal by means of a simplified model with three total contexts and three individuals (an ostrich, a chicken and a centimeter unit object). According to my proposal, we consider individuals' degrees in tall as specified because (i) the ratios between (values representing) heights do not vary across total contexts, e.g., as the ostrich in Table 1 is twice as tall as the chicken, the ratio between the degrees of the ostrich and the chicken is 2 in every total context, and (ii) a set of unit objects exists, $D_{\mathrm{cm}}=\left\{\mathrm{d}_{\mathrm{cm}}\right\}$, s.t. $\mathrm{d}$ is $r$ centimeters ( $\mathrm{cm}$ ) tall iff the ratio between d's degree and the centimeter unit objects' degree is r, e.g., as the ratio between the degrees of the ostrich and the centimeter unit object is 100 in every total context in our example, the ostrich is 100 centimeters tall is true in it.

Some unit names (like Celsius) are interpreted by other interpretation rules. Yet we will see in Sect. 3.4 that speakers often wrongly presuppose that Celsius is interpreted by rule (10), i.e. this rule is productively used by speakers, while other rules invented by scientists are not. In Part 3, I describe in detail the various consequences of this analysis.

\section{Consequences}

The main advantage of the analysis presented above is that it captures not only the interpretation, but also the puzzling limited distribution of measure phrases, as argued 
in detail in Sects. 3.1-3.6. In addition, it helps clarify one type of circumstances in which between-predicate comparisons are licensed, as argued in Sect. 3.7.

I have argued for (11):

(11) In actual contexts c, speakers feel they have information about entities' degrees in tall only because the following two preconditions hold:

a. Precondition ( $i$ ): The ratios between entities' degrees are given (contextinvariant) numbers $\left(\forall \mathrm{d}_{1}, \mathrm{~d}_{2} \in \mathrm{D}, \exists \mathrm{r} \in \mathfrak{R}: \forall \mathrm{t} \in \mathrm{T}_{c}, \mathrm{f}_{\text {tall,t1 }}\left(\mathrm{d}_{1}\right) / \mathrm{f}_{\text {tall,t1 }}\left(\mathrm{d}_{2}\right)=\mathrm{r}\right)$.

b. Precondition (ii): There is a consensus regarding a set of unit-objects (e.g., the meters) that serves as a reference point, so that any entity $\mathrm{d}$ is mapped to a given (context-invariant) number, representing the ratio between d's degree and the unit objects' degree in tall.

In the following, I show that in languages that allow adjectives to combine with measure phrases, an adjective does not license unit names and numerical degree predicates iff at least one of these preconditions is violated.

\subsection{Violations of precondition (ii): absence of a consensus regarding unit-objects}

My proposal predicts that the absence of conventional unit objects will result in vagueness concerning the mapping of entities to numbers. I propose that some adjectives have no unit names associated with them because it is impossible to determine a convention for them regarding a set of unit objects. Consequently, we have the impression that these adjectives do not map entities to numerical degrees.

Consider, for instance, happy. Emotions are internal states. It is hard to come up with conventions as to which emotional extent should be mapped to degree 1, 2, 3, etc. Even if one speaker treats a certain internal state as a unit object, no other speaker has access to this state. So no object d can be agreed upon by all the community of speakers to constitute a unit object. This is the case even if any one of the speakers associates with happy internal (subjective and non-conventional, but nonetheless actual) means of additively measuring happiness intensities (including a suitable 'concatenation' relation for such intensities).

Similarly, while weight can be measured by kilograms, the internal states of speakers when they lift objects (their feeling of the objects being heavy, light, etc.) cannot be measured by conventionally established unit names. If a language maps a predicate to the latter type of degrees, the predicate will not license unit names and numerical degree modifiers. But this does not show that predicates do not map entities to numbers (contrary to, for instance, Moltmann's 2006 view). In fact, when no unit name is explicitly mentioned, it is rather meaningless to say that something is tall to degree 456 (456 what? Kilometers? Meters? Inches?) In adjectives like happy, this is always the situation.

This proposal improves upon non-numerical theories (cf., Moltmann 2006) because it accounts for the compatibility of happy with ratio and difference modifiers.

For example, Dan is twice as happy as Sam is a claim concerning the ratios between the arguments' happiness degrees (with no reference to unit objects): 
(12) $\llbracket$ Dan is twice as happy as Sam $\rrbracket_{c}=1$ iff

$\forall \mathrm{t} \in \mathrm{T}_{\mathrm{c}}: \quad \mathrm{f}_{\text {happy, } \mathrm{t}}\left(\llbracket \mathrm{Dan} \rrbracket_{\mathrm{t}}\right)=2 \times f_{\text {happy, } \mathrm{t}}\left(\llbracket \operatorname{Sam} \rrbracket_{\mathrm{t}}\right)$.

In addition, we can present a unified analysis of comparative morphemes with and without numerical degree modifiers, whereby the interpretation of these morphemes is mediated by a difference operation, creating difference modifiers, as demonstrated in (13) (for more discussion see Sect. 4.1):

(13) a. [Dan is 2 meters taller than Sam $\rrbracket_{\mathrm{c}}=1$ iff

$\forall \mathrm{t} \in \mathrm{T}_{\mathrm{c}}: \quad \mathrm{f}_{\text {tall, } \mathrm{t}}\left(\left[\mathrm{Dan} \rrbracket_{\mathrm{t}}\right)-\mathrm{f}_{\mathrm{tall}, \mathrm{t}}\left(\llbracket \operatorname{Sam} \rrbracket_{\mathrm{t}}\right)=2 \times \mathrm{r}_{\mathrm{m}, \mathrm{t}}\right.$.

b. [Dan is happier than Sam $\rrbracket_{\mathrm{c}}=1$ iff

$\forall \mathrm{t} \in \mathrm{T}_{\mathrm{c}}, \quad \exists \mathrm{r} \in \mathfrak{R}, \mathrm{r}>0: \quad \mathrm{f}_{\text {happy,t }}\left(\left[\mathrm{Dan} \rrbracket_{\mathrm{t}}\right)-\mathrm{f}_{\text {happy, } \mathrm{t}}\left(\llbracket \operatorname{Sam} \rrbracket_{\mathrm{t}}\right)=\mathrm{r}\right.$.

We see that speakers do not need to know the degrees of entities they refer to, only the ordering or ratios between their degrees. These are available to them (cf., Sects. 2.2-2.3).

Notice that speakers often assert, for instance, that they are twice as happy, as a manner of speech - a figurative way of stating that they are much happier. However, this does not show that twice as happy is ungrammatical. Presumably, we may not be familiar nor understand the nature of any ratio-scale measuring means for happy. Still, there is no a priori reason to think that such measurements are impossible (we do not possess information according to which perceptual and emotional measurements of our experiences must be non-ratio-scale). For this reason we do not judge utterances of expressions such as twice as happy ungrammatical, even if we do not completely understand what they mean (we will see in the next Section that this is not the case for expressions like twice as short).

The problem more generally is that while it is easy to imagine what the concatenation relation of tall is, in other cases the nature of the relation is far from being obvious. For example, while placing two entities end to end gives us their concatenation with respect to height, it does not give us, say, their concatenation with respect to heat. Nor does mixing, say, two amounts of water, give us their concatenation with respect to heat. Still, it is a known physical fact that the heat quantity (energy) in two amounts of water equals the sum of heat quantities in each one. Thus, heat measures can be additive, and if an adjective like hot is associated with measures of heat, it can be conceived of as additive with respect to heat (cf. the Krantz et al. 1971 analysis of heat measures in Kelvin units). ${ }^{9}$ We see that concatenation relations are measure-specific and sometimes determined in unobvious ways. Therefore, we are not capable of giving a precise definition for every adjectival concatenation relation. But nor is it our job, as speakers (or semanticists), to do so. Rather, unless there are reasons to believe otherwise, speakers accept the possibility that a concatenation relation can be defined for a given adjective, and this suffices for the licensing of ratio-based modifiers. ${ }^{10}$

\footnotetext{
9 As is convincingly argued by Schwarzschild (2006), the absence of connections between, e.g., quantities of heat and water, signifies non-monotonicity, a semantic property, which has important syntactic reflexes. Yet, it is irrelevant for additivity with respect to heat, in the very same way as the absence of connections between height and, say, length, volume, weight or substance of entities is irrelevant for additivity with respect to height.

10 Note that the same adjective can be associated with different measures in different contexts of use, e.g. hot and warm can be associated with measures of heat (energy), measures of external temperature (the heat
} 
Furthermore, even when speakers are willing to accommodate the presupposition that additive measuring systems exist for happiness (say, that their subjective emotional and perceptual measures are additive), they cannot always be precise about degree ratios, or they may not find the precise ratios important, e.g., "on Monday I was twice as happy as I was on Sunday" is a very precise conclusion to reach through introspection. Speakers may be reluctant to commit themselves to this level of precision regarding their emotions.

To summarize, I propose that it is for these reasons, and not because it is ungrammatical in the literal sense, that twice as happy is used as a manner of speech. We can reason with statements like I am ten times happier now than I used to be once or I am twice as happy now as I was ten minutes ago. We have no information proving that we can have no additive method for measuring happiness, though no such method has as yet become conventional.

\subsection{Violations of precondition (i): absence of information about ratios between degrees}

While we may acknowledge the ratios between, say, our degrees of happiness on separate occasions, we can hardly ever acknowledge the ratios between degrees of entities in predicates like short. This is illustrated by the fact that ratio modifiers are less acceptable with short than with tall or long (cf. (14)-(15)). This contrast characterizes many antonym pairs (Horn 1972; Seuren 1978; von Stechow 1984b; Bierwisch 1989; Kennedy 2001).

(14) a. The table is twice as tall/ long/ wide/ big as the chair

b. \#The table is twice as short/ small/ narrow as the chair

(15) a. Dan is twice as fast/ old/ smart/ happy as Sam

b. \#Dan is twice as slow/ young/ foolish/ unhappy as Sam

Sassoon (2009) empirically supports the claim that ratio modifiers are less often used with negative adjectives than with their positive antonyms (e.g., short vs. tall), based on a study of Google search-results of equatives and ratio comparisons with pairs of antonym adjectives.

Accordingly, the present analysis predicts that, in the absence of a specification of (or information concerning) ratios between degrees (which is a violation of condition (i), cf. (11a)), numerical degree predicates will not be licensed, i.e. we directly explain why negative adjectives fail to combine with measure phrases to form numerical degree predicates, e.g., the infelicity of \#two meters short.

\footnotetext{
Footnote 10 continued

of an entity divided by its volume, or, perhaps, the heat in that minimal subpart of an entity which is being measured with a thermometer), measures of perceived temperature (the extent to which we feel stimuli to be warm, as in I'm warm), measures of the extents to which entities make us feel warm (e.g., the extents to which shoes or blankets are warm, i.e. cause the individuals wearing them to feel warm), measures of emotional characteristics, etc. Similarly, I believe that, in principle, adjectives like happy may receive 'objective' interpretations (such as measures of brain activation or physiological measures of well-being). Furthermore, given the direct access that we have to our own subjective experiences, even subjective measures may be additive. The points at which we cease to feel happiness, weight, warm or cold may form the zero point for these internal measures.
} 


\subsection{Measure phrases in comparison statements}

Still, numerical degree predicates are acceptable in the comparative form of either positive or negative adjectives (cf. Kennedy 1999).

(16) a. \#Dan is $2 \mathrm{~m}$ short

b. Dan is $2 \mathrm{~m}$ shorter than Sam

In fact, in actual contexts, we can positively say that Dan's degree in short is $n$ meters bigger than Sam's iff Sam's degree in tall is $n$ meters bigger than Dan's. Why doesn't short specify degree ratios, while shorter does? Sassoon (2009) accounts for these facts by assigning any negative adjective, in any index $t$, a degree function that linearly reverses and linearly transforms the degrees of its positive antonym. She proposes that for any context $t \in T_{c}$ there is a constant $\operatorname{Tran}_{\text {short }, t} \in \Re$, such that $f_{\text {short, }}$ assigns any $\mathrm{d}$ in $\mathrm{D}$ the degree $\operatorname{Tran}_{\text {short, } \mathrm{t}}-\mathrm{f}_{\text {tall,t }}(\mathrm{d})$ :

$$
\forall \mathrm{t} \in \mathrm{T}_{\mathrm{c}}, \exists \operatorname{Tran} \in \Re \text {, s.t. } \forall \mathrm{d} \in \mathrm{D}, \mathrm{f}_{\text {short }, \mathrm{t}}(\mathrm{d})=\operatorname{Tran}-\mathrm{f}_{\text {tall, } \mathrm{t}}(\mathrm{d})
$$

The motivation for assuming that degree-functions of negative adjectives are reversed compared to the functions of their positive antonyms is rather straightforward. This assumption represents the fact that, e.g., Dan is taller than Sam iff Sam is shorter than Dan, i.e. the ordering between the degrees assigned to any two entities by short is reversed in comparison with the ordering between the degrees assigned to them by tall. ${ }^{11}$

The motivation for transformation values is the following. We can positively say that an adjective like tall, which is linked to conventional additive measuring systems, maps entities with no height to zero. The outcome of measuring entities with no height, such as the surface of the floor, with a ruler (any ruler) is systematically the number zero. ${ }^{12,13}$ So in every $\mathrm{t} \in \mathrm{T}_{\mathrm{c}}, \mathrm{f}_{\text {tall, } \mathrm{t}}$ maps entities with no height to 0 (it's additive). However, consider the adjective short. If, in every total context $\mathrm{t}$ of $\mathrm{T}, \mathrm{f}_{\mathrm{tall}} \mathrm{t}$ is additive (it maps entities with no height to 0 ), and short is not transformed in a context $\mathrm{c}\left(\operatorname{Tran}_{\text {short }, \mathrm{t}}=0\right.$ in every total context $\mathrm{t}$ of $\mathrm{T}_{\mathrm{c}}$, i.e. $\left.\mathrm{f}_{\text {short }, \mathrm{t}}=-\mathrm{f}_{\text {tall, }, \mathrm{t}}\right)$, then the degree of entities $d$ with no height in short is predicted to be 0 in c (because in every $\mathrm{t} \in \mathrm{T}_{\mathrm{c}}$ it is $\left.-\mathrm{f}_{\mathrm{tall}, \mathrm{t}}(\mathrm{d})=-0=0\right)$. But is this so? Can we positively say that short maps entities with no height, such as the surface of the floor, to zero? (or, in other words, that the surface of the floor is short to degree zero?) Not really. As tall does not have a maximum point (no height is "the tallest"), the antonym short does not have

\footnotetext{
11 I refrain from using reversed functions that are not based on a minus operations (say the function $\lambda \mathrm{d} \in$ D. $\left.1 / \mathrm{f}_{\text {tall,t }}(\mathrm{d})\right)$, for otherwise $y$ is $2 \mathrm{~cm}$ shorter than $x$ would not mean the same anymore as $x$ is $2 \mathrm{~cm}$ taller than $y$ (e.g., the difference between 8 and $6 \mathrm{~cm}$ is $2 \mathrm{~cm}$, but the difference between $1 / 8 \mathrm{~cm}$ and $1 / 6 \mathrm{~cm}$ is not $2 \mathrm{~cm})$.

12 Speakers can also examine their intuitions about entities with almost no height, which tall maps to a very small degree compared to the degrees of entities with notable amounts of height.

13 Additive height-functions, as opposed to transformed ones, must map entities with no height to zero (and entities with height to bigger degrees), for otherwise they will not adequately represent height ratios. To see this, consider, a function $\mathrm{f}$ that maps some entity $\mathrm{d}_{0}$ with no height (say, the surface of the floor) to, say, $1 / 2$ and maps a meter unit-object to 1 . The ratio between $\mathrm{d}_{0}$ 's value and the value of a meter unit-object is then the non-zero number $1 / 2$ (it is half a meter tall), while the ratio between $\mathrm{d}_{0}$ 's height and the height of a meter unit-object (or any other object) is 0 . Thus, $\mathrm{f}$ does not adequately represent height ratios.
} 
a minimum point (a zero). I propose to represent intuitions about an unspecified zero point with an unspecified transformation value. Hence, the degree function of short transforms height quantities by a constant, $\operatorname{Tran}_{\text {short }}$, that varies across total contexts, rendering the zero point undetermined. ${ }^{14}$

$$
\neg \exists \mathrm{n} \in \Re: \quad \forall \mathrm{t} \in \mathrm{T}_{\mathrm{c}}, \operatorname{Tran}_{\text {short }, \mathrm{t}}=\mathrm{n} .
$$

But when $\operatorname{Tran}_{\text {short }, \mathrm{t}} \neq 0, \mathrm{f}_{\text {short, } \mathrm{t}}$ is not additive-it does not represent ratios between entities' heights. If, for instance, $\mathrm{f}_{\text {tall, } \mathrm{t}}\left(\mathrm{d}_{1}\right)=\mathrm{f}_{\text {tall, } \mathrm{t}}\left(\mathrm{d}_{2}\right)=5$, then by additivity $\mathrm{f}_{\text {tall, } \mathrm{t}}\left(\mathrm{d}_{1} \bigoplus\right.$ height $\left.\mathrm{d}_{2}\right)=10$. But, say, a function $\mathrm{f}_{1-\mathrm{f}}$ that maps each $\mathrm{d}$ to $\left(1-\mathrm{f}_{\text {tall, }}(\mathrm{d})\right)$ is s.t. $\left(\mathrm{f}_{1-\mathrm{f}}\left(\mathrm{d}_{1}\right)=\mathrm{f}_{1-\mathrm{f}}\left(\mathrm{d}_{2}\right)=-4\right)$ and $\left(\mathrm{f}_{1-\mathrm{f}}\left(\mathrm{d}_{1} \bigoplus\right.\right.$ height $\left.\mathrm{d}_{2}\right)=1-f_{\text {tall, }}\left(\mathrm{d}_{1} \bigoplus\right.$ height $\left.\left.d_{2}\right)=-9 \neq(2 \times-4)\right)$. The ratio between the degrees of $d_{1} \bigoplus$ height $d_{2}$ and $d_{1}$ is $9 / 4$, while the ratio between their heights is $8 / 4$.

The fact that the degrees of negative adjectives like short fail to represent height ratios has the following consequences.

First, ratio modifiers are less acceptable with negative adjectives than with their positive antonyms (cf., the infelicity of, e.g., \#Dan is twice as short as Sam).

Second, negative adjectives do not license unit names. The semantic value of unit names, e.g. inches, crucially relies on the fact that the function denoted by its adjectival argument $\mathrm{P}$ in each context of use encodes the ratios between the amounts of P-hood in entities (so to speak) and the amount of P-hood in a unit object. Thus, adjectives whose functions do not encode these ratios cannot form arguments for unit names. Had the degree function of tall been transformed, like the one of short, inches would not constitute possible units for tall. ${ }^{15}$

Nor can we use negative adjectives with numerical degree phrases construed from

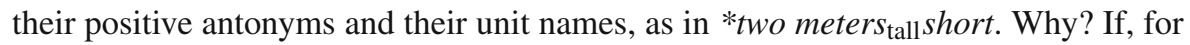
instance, in c, tall maps some d to $\left.2 \mathrm{~m}\left(\forall \mathrm{t} \in \mathrm{T}_{\mathrm{c}}, \mathrm{f}_{\mathrm{tall}, \mathrm{t}} \mathrm{d}\right)=2 \times \mathrm{r}_{\mathrm{m}, \mathrm{t}}\right)$, short maps $\mathrm{d}$ to $\operatorname{Tran}_{\text {short }}-2 \mathrm{~m}\left(\forall \mathrm{t} \in \mathrm{T}_{\mathrm{c}}, \mathrm{f}_{\text {short }, \mathrm{t}}(\mathrm{d})=\operatorname{Tran}_{\text {short }, \mathrm{t}}-2 \times \mathrm{r}_{\mathrm{m}, \mathrm{t}}\right)$ As the transformation value, $\operatorname{Tran}_{\text {short, } t}$, varies across total contexts, we cannot classify entities as $2 \mathrm{~m}$ short in c: $\neg \exists \mathrm{d}: \forall \mathrm{t} \in \mathrm{T}_{\mathrm{c}}, \mathrm{f}_{\text {short } \mathrm{t}}(\mathrm{d})=2 \times \mathrm{r}_{\mathrm{m}, \mathrm{t}}$.

However, in computing degree-differences, the transformation values of the two degrees cancel one another:

(19) a. $\forall \mathrm{t} \in \mathrm{t}_{c}, \mathrm{~d}_{2}$ is $2 \mathrm{~m}$ taller than $\mathrm{d}_{1}$ (i.e., $\mathrm{f}_{\text {tall, } \mathrm{t}}$ maps $\mathrm{d}_{2}$ to some $\mathrm{n} \in \Re$ and $\mathrm{d}_{1}$ to $\mathrm{n}-2 \times \mathrm{r}_{\mathrm{m}, \mathrm{t}}$; the difference between these degrees is $2 \times \mathrm{r}_{\mathrm{m}, \mathrm{t}}$ ) iff

b. $\forall \mathrm{t} \in \mathrm{T}_{\mathrm{c}}, \mathrm{d}_{1}$ is $2 \mathrm{~m}$ shorter (i.e., $\mathrm{f}_{\text {short }, \mathrm{t}}$ maps $\mathrm{d}_{2}$ to $\operatorname{Tran}_{\text {short }, \mathrm{t}}-\mathrm{n}$ and $\mathrm{d}_{1}$ to $\operatorname{Tran}_{\text {short, } t}-\left(\mathrm{n}-2 \times \mathrm{r}_{\mathrm{m}, \mathrm{t}}\right)$; the difference between these degrees is still $2 \times r_{m, t}:\left(\operatorname{Tran}_{\text {short }, t}-\left(n-2 \times r_{m, t}\right)-\left(\operatorname{Tran}_{\text {short }, t}-n\right)=\mathbf{2} \times \mathbf{r}_{\mathrm{m}, \mathrm{t}}\right)$.

\footnotetext{
14 In some semantic theories (von Stechow 1984b; Kennedy 1999), entities with (almost) no height are mapped to (a degree that approximates) infinity (formally, they are mapped to the largest interval $(0, \infty)$, not the zero interval $(0,0))$. So in these theories, too, the degree function of short transforms height quantities by a constant.

15 The licensing conditions for unit names are stricter than those for ratio modifiers. Although in some ad-hoc contexts, we may accept ratio statements such as this story is twice as short as that one (say, when we measure short stories by word counts), the ungrammaticality of e.g. two words short persists. Why? Presumably because unlike ratio-modifiers, any unit name must be conventionally (lexically) linked to a set of adjectives, all of which must be ratio-scale ones (cf., Sects. 1.3 and 2.3). Thus, speakers won't link unit names to adjectives like short which are predominantly not interpreted as ratio-scale, despite the few ad-hoc contexts in which they are.
} 
So the differences between any two given degrees are preserved under the reversal induced by $f_{\text {short, } t}$ in every total context $t$ of $T_{c}$ of actual contexts $c$. For this reason, we can felicitously say that entity-pairs stand (or do not stand) in, e.g., the relation 'two meters tall $_{\text {shorter'. }}{ }^{16}$

For a more elaborate discussion of negative adjectives see Sassoon (2009). The crucial point for our present purposes is that facts pertaining to the licensing of measure phrases with negative adjectives receive a straightforward explanation if negative adjectives are analyzed as denoting interval-scale properties (i.e., the values of their degree functions represent ordering and differences, but not necessarily ratios, between individuals on the respective dimensions, cf. Sect. 1.2), e.g, being a negative adjective, short's measure must be linearly reversed with respect to some height measurement; however, for any height measurement, infinitely many measures exist that are all linearly reversed with respect to it, most of which are transformed and hence non additive. No rule of grammar rules out total contexts in which these form the interpretation of short. This creates vagueness with regard to degree ratios that renders ratio-based degree constructions inherently uninterpretable. ${ }^{17}$

\subsection{Celsius}

The interpretation of some units is not generated by the general 'linguistic' rule for the interpretation of unit names proposed in (10). Rather, their interpretation is derived from the interpretation of other unit names in some systematic way. For example, presumably, the interpretation of 1 kilometer long in total contexts $t$ is derived from the interpretation of the unit name meter. It is to the set of entities $d$ in $D$, such that $f_{\text {long, } t}(d)$ $=1000 \times \mathrm{f}_{\text {long }, \mathrm{t}}\left(\mathrm{d}_{\mathrm{m}}\right)$, for any meter unit-object $\mathrm{d}_{\mathrm{m}} \in \mathrm{D}_{\text {meter-long. The interpretation }}$ of Celsius is even more complicated in that its derivation involves transformation of (additive) Kelvin degrees by a conventionally established value. For any n, entities that are "n Kelvin hot" are "n-273 Celsius hot". So a box is 1 degree Celsius iff it is 274 degrees Kelvin, but a box is 1 degree Celsius more than a shelf iff the box is 1 degree Kelvin more than the shelf, not 274 degree Kelvin more. As the transformation value is fixed (273) and entities' Kelvin degrees (the ratios between their degree in hot and the Kelvin unit objects' degree) are context-invariant numbers, so are also entities' Celsius degrees.

\footnotetext{
16 Schwarzschild (2005) observes that some predicates, (like German schwer when meaning 'rich') can combine with measure phrases (as in, e.g., 46,000 Euro schwer) though they cannot be used in a comparative (*10 Euro schwerer, '10 Euro richer'). I analyzed tall (or its projection) in, e.g., two meters tall, as a semantic argument of the unit name meter. Yet, I would guess that in Schwarzschild's examples the adjectives take the measure phrases as arguments (like English worth). The result is a binary function (whether an entity has/worth 46,000 Euros is not a matter of degree). Adjectives with binary functions cannot combine with comparative morphemes (cf., \#a primer number and \#more prime). They denote ordinal or even nominal-scales (cf. Sect. 1.2).

17 Regarding the felicity of the German example -10 degrees kalt ('-10 degrees cold'), speakers report that it actually conveys that its " -10 degrees, which is cold", i.e. the unit name takes $\mathrm{f}_{\text {heat, } \mathrm{t}}$ as an argument (a non-reversed ratio-scale function). The use of kalt only adds an evaluative implication. Future research should discover the circumstances in which such uses are acceptable (same for uses of thirty springs young in English and Dutch).
} 
Note that we can achieve correct semantic results by ignoring our semantic intuitions and analyzing Celsius $_{\text {hot }}$, not as a unit name, but, rather, as a predicate denoting a transformed measure of heat, i.e. the function that maps every d in D to d's degree in Kelvin (the ratio between d's heat and the heat in a Kelvin unit object, $\mathrm{d}_{\mathrm{K}}$ ), minus 273 , as shown in (20a). In particular, we see in (20b) that this analysis gives the right results for comparison statements.

(20) a. For any $\mathrm{d} \in \mathrm{D}$ and $\mathrm{t} \in \mathrm{T}, \mathrm{f}_{\text {Celsius,t }}(\mathrm{d})=\mathrm{f}_{\text {hot }}(\mathrm{d}) / \mathrm{r}_{\text {Kelvin, } \mathrm{t}}-273$

b. 【The box is 2 degrees Celsius hotter than the shelf $\rrbracket_{\mathrm{t}}=1$ iff $\mathrm{f}_{\text {Celsius, }} \mathrm{t}\left(\left[\right.\right.$ the box $\left.\rrbracket_{\mathrm{t}}\right)-\mathrm{f}_{\text {Celsius, }}\left(\left[\llbracket\right.\right.$ the shelf $\left.\rrbracket_{\mathrm{t}}\right)=2$ iff $\exists \mathrm{d}_{\mathrm{k}} \in \mathrm{D}_{\mathrm{K}}:\left(\mathrm{f}_{\text {hot, }}\left(\llbracket\right.\right.$ the box $\left.\left.\rrbracket_{\mathrm{t}}\right) / \mathrm{f}_{\text {hot }, \mathrm{t}}\left(\mathrm{d}_{\mathrm{k}}\right)\right)-273-$ $\left(\mathrm{f}_{\text {hot }, \mathrm{t}}\left(\llbracket\right.\right.$ the shelf $\left.\left.\rrbracket_{\mathrm{t}}\right) / \mathrm{f}_{\text {hot }, \mathrm{t}}\left(\mathrm{d}_{\mathrm{k}}\right)\right)-273=2$ iff $\mathrm{f}_{\text {hot }, \mathrm{t}}\left(\llbracket\right.$ the box $\left.\rrbracket_{\mathrm{t}}\right)-\mathrm{f}_{\text {hot }, \mathrm{t}}\left(\right.$ [the shelf $\left.\rrbracket_{\mathrm{t}}\right)=2 \times \mathrm{r}_{\text {Kelvin }, \mathrm{t}}$ The ratio of heat in the box and in a Kelvin unit-object minus the ratio of heat in the shelf and in a Kelvin unit-object equals two (so the box is 2 degrees Kelvin hotter).

Furthermore, note that the numbers that Celsius assigns to entities do not directly represent quantities of heat (or temperature). In accordance, they are not additivethey do not adequately represent the fact that the heat in two cells together equals the sum of heat in the two separate cells (i.e. that for any $\mathrm{t}, \mathrm{f}_{\text {hot, } t}\left(\mathrm{~d}_{1} \oplus \mathrm{d}_{2}\right)=\mathrm{f}_{\text {hot, } t}\left(\mathrm{~d}_{1}\right)+$ $\left.\mathrm{f}_{\text {hot, }}\left(\mathrm{d}_{2}\right)\right)$. For example, if cells $\mathrm{d}_{1}$ and $\mathrm{d}_{2}$ each contains the heat of $2^{\circ} \mathrm{K}\left(2 \times \mathrm{r}_{\text {Kelvin }}\right)$, each falls under (2-273) degrees Celsius, and the heat contained in both of them together, the heat in $4 \mathrm{~K}$ unit objects $\left(4 \times \mathrm{r}_{\text {Kelvin }}\right)$, falls under (4-273) degrees Celsius. But $(2-273)+(2-273)=(4-546) \neq(4-273)$. Thus, Celsius does not assign $\mathrm{d}_{1} \bigoplus$ $\mathrm{d}_{2}$ the sum of numbers it assigns to $\mathrm{d}_{1}$ and $\mathrm{d}_{2}$. The heat in any entity that is an instance of 2 degrees Celsius is not twice the heat in an entity which is an instance of 1 degree Celsius.

In fact, handbooks of measurement theory are equipped with explanations as to why it is senseless to say that 4 degrees Celsius is twice as hot as 2 degrees Celsius. However, linguistically, speakers analyze Celsius as a unit name, not as a predicate whose degrees are transformed Kelvin units! Thus, despite these explanations, they cannot help judging this sentence to be perfectly acceptable (just like the sentence 4 meters is twice as long as 2 meters). I submit that this further supports my proposal that speakers interpret unit names in terms of the interpretation rule in (10), e.g. speakers analyze the statement The box is 2 degrees Celsius hotter than the shelf as if it means: " $f_{\text {hot }, \mathrm{t}}\left(\left[\right.\right.$ the box $\left.\rrbracket_{\mathrm{t}}\right)-f_{\text {hot, } \mathrm{t}}\left(\llbracket\right.$ the shelf $\left.\rrbracket_{\mathrm{t}}\right)=2 \times \mathrm{r}_{\text {Celsius, }}$ (in every $\mathrm{t}$ of $\left.\mathrm{T}_{\mathrm{c}}\right)$ ", which is, of course, erroneous. The difference between the two given degrees is $2 \times \mathrm{r}_{\text {Kelvin }}$. This mistake reveals the fact that a generative rule, such as the one in (10), is used productively when unit names are to be interpreted. Other rules (such as the one for Celsius) are 'marked', or 'extra grammatical', in the sense that they are only available for those who are familiar with measurement theory and/or the scientific definition of a given unit name, e.g., Celsius. In that Celsius resembles other noun phrases whose scientific definitions are different from the ones native speakers are predisposed to use. 
3.5 Sources of crosslinguistic variance in felicity of measure phrases with positive adjectives

Some positive adjectives resemble negative ones in terms of the licensing of measure phrases. For example, (21a) resembles (21b) in being somewhat awkward. However, (21c-d) are perfectly acceptable (Kennedy 2001). So in terms of the licensing of numerical degree modifiers, warm resembles its negative antonym cold and not other positive adjectives.

(21) a. \#The box is $30^{\circ}$ warm

b. \#The box is $30^{\circ}$ cold

c. The box is $30^{\circ}$ warmer than the shelf

d. The box is $30^{\circ}$ colder than the shelf

My proposal improves upon other accounts of antonymy (cf. von Stechow 1984a; Kennedy 1999), because it can capture facts pertaining to positive adjectives like warm.

First, positive adjectives for which additive (ratio-scale) measures exist may have transformation values, too (even though their measures are not reversed). Temperature predicates are an example. Well established additive tools for measuring temperature, e.g. Kelvin thermometers, exist. However, in actual practice, more often than not, temperature is measured by transformed (interval-scale) thermometers. The reasons are pragmatic. While we never encounter entities with absolutely no temperature ('zero Kelvin'), we often experience events or entities that measure $273^{\circ} \mathrm{K}$. Thus, the use of transformed measures, such as the Celsius scale (which maps such entities to zero) is convenient. I propose that the existence of concepts like Celsius supports the view that in actual contexts positive adjectives (e.g., temperature predicates) often denote transformed measures.

To summarize, the point of $0-\mathrm{K}$ heat $\left(-273^{\circ} \mathrm{C}\right)$ is hardly ever experienced or talked about by speakers who are not-scientists. Thus, for them, any choice of a zero is arbitrary (which, formally, means that in different total extensions of any actual context c, predicates like warm are associated with different transformation values). Only if a unit name is explicitly used, must an additive interpretation be accommodated (by switching to an extension $\mathrm{c}$ / of $\mathrm{c}$ where the transformation value equals zero for any $t$ of $T_{c}^{\prime}$ ). In addition to capturing our vague intuitions regarding zero temperature, the association of warm with an unspecified transformation value renders, e.g., \#2 degrees warm, but not 2 degrees warmer, infelicitous, as desired (cf., Sect. 3.3). Furthermore, cross linguistic variations in the licensing of numerical degree predicates are expected, since languages may vary as to whether the measures associated with a given positive adjective will be transformed or not. ${ }^{18}$

A second source for cross linguistic variation in the licensing of measure phrases with positive adjectives relates to differences in interpretation, e.g., languages may vary as to whether predicates like heavy or warm are associated with measures of

\footnotetext{
18 'Extent'-based analyses of negative adjectives (Seuren 1978; von Stechow 1984b; Bierwisch 1989; Kennedy 1999, 2001, etc.) fail to capture these facts (for details see Sassoon 2009). This is a serious problem given the pervasiveness of these phenomena. Thus, the present proposal improves upon 'extent' theories of antonymy in terms of the set of facts it adequately captures, while employing the simpler and more intuitive assumption whereby gradable adjectives map entities to single points.
} 
Table 2 A summary of my proposals in Sects. 3.1-3.5

\begin{tabular}{lllll}
\hline & Type & Measure phrases & Ratio phrases & Explanation \\
\hline Tall & $\begin{array}{c}\text { Ratio; specified } \\
\text { unit objects } \\
\text { Ratio; no unit } \\
\text { objects }\end{array}$ & $5 \mathrm{~m}$ tall & Twice as tall & $\begin{array}{c}\text { Preconditions } \\
\text { satisfied }\end{array}$ \\
Short, warm & $\begin{array}{c}\text { Interval } \\
\text { (Transformed } \\
\text { function) } \\
\text { vatiolation (ii) is } \\
\text { shorter }\end{array}$ & $* 5 \mathrm{~m}$ short & Twice as happy & \#twice as short \\
& $\begin{array}{c}\text { Precondition (i) is } \\
\text { violated }\end{array}$ \\
& function) & $5 \mathrm{~m}$ shorter & $\begin{array}{c}\text { Z is twice as } \\
\text { shorter than } \mathrm{x} \text { as } \\
\text { y is }\end{array}$ & $\begin{array}{c}\text { Tran } \\
\text { out }\end{array}$ \\
\hline
\end{tabular}

external or internal states or both (cf. Sect. 3.1). Recall that with internal measures, measure phrases are ruled out due to violation of condition (ii) (absence of conventional unit objects), whether the given measure is ratio-scale or not.

My proposals so far are summarized in Table 2 above. Next I discuss two additional sources for crosslinguistic variations, pertaining to the interpretation of unit names (not of adjectives): Redundancy and Adj/Nom parametric variation.

The first has to do with the fact that the role of the adjectival argument of unit names in degree constructions is to specify the dimension (and hence measure) to be used. Thus, the adjectival argument of one-dimensional unit names (unit names that can only be associated with adjectives that share one and the same dimension) need not be explicitly mentioned. For example, mentioning the adjectival argument hot is completely superfluous in examples like yesterday was 30 degrees Celsius $_{\text {hot }}$, as the unit name Celsius only combines with adjectives whose degree function measures entities' heat. Many (if not most) unit names can only be associated with adjectives that share a dimension (cf. Kilogram, Pound, Volt, Decibel, Hertz, Kelvin, Celsius, etc.) This very fact may have rendered the explicit mention of an adjective in numerical degree constructions (as in two meters tall) unacceptable in many languages (leaving only 'bare' measure phrases like two meters acceptable). ${ }^{19}$

In fact, the predicative argument of unit names remains implicit whenever the linguistic context renders its mention redundant. For example, its mention is not redundant in examples such as Dan is one inch tall or one inch wide, as it is only by virtue of the adjectival arguments that we can distinguish between the numerical degree predicates in these statements. However, its mention is redundant in examples such as Dan is one inchtall taller than Sam. The adjective that explicitly occurs here is an argument of the morpheme er, not of the unit name inch, but at the same time it also informs

\footnotetext{
${ }^{19}$ For a similar argument see van Rooij (to appear) and the discussion in Murphy (2006). Note however, that warm may not combine with unit names also due to its transformed measure, as explained earlier, for redundancy does not explain our vague intuitions about the zero point. I propose that whenever the zero point of a ratio-scale measure is not easily perceived or is relatively unimportant (say, if we rarely refer to it), positive adjectives associated with that measure may, in some languages, have transformation values. A case in point may be the French entry for 'tall', whose failure to combine with measure phrases cannot be due to redundancy.
} 
the listeners that the units must be of height, rendering the mention of the adjectival argument of inch superfluous.

As for the phenomenon I call "Adj./Nom parametric variation", note that both ratio-scale adjectives and their nominalizations (e.g., tall-height, wide-width, happyhappiness) can serve equally well in specifying the dimension of measurement in the use of a unit name. This explains the fact that some languages (e.g. Hebrew), unlike English, systematically prohibit combinations of adjectives with measure phrases, but do allow for numerical degree predicates with nominalizations (as in, e.g., gova (shel) shney meter, 'height (of) two meters').

To summarize, there are at least four reasons for cross linguistic variations in the licensing of measure phrases with positive adjectives, pertaining to (i) transformation values; (ii) differences in interpretation; (iii) redundancy, and (iv) $\operatorname{adj} \backslash$ nom parametric variations.

\subsection{Positive adjectives with interval-scale measures, the psychophysical perspective}

Psychophysics is the study of the measures we associate with stimuli such as heat, sound, and pain, including the connections between the perceived intensity of stimuli and their objective intensity as measured by external means (if there are any). Do the findings in this research area support the view that positive measures often encode degree differences, but not ratios? ${ }^{20}$

Until the end of the twentieth century, the Weber-Fechner law, and especially Stevens' power law (Stevens 1957) have been among the most influential theories regarding the relationship between the magnitude of a physical stimulus and its perceived intensity or strength ('sensation'). These theories advance the idea that sensation increases as the logarithm of stimulus magnitude or as a power function of stimulus magnitude, respectively. These theories presuppose that subjects can productively use ratio-scale measurements, i.e. they can always judge whether a given stimulus is, say, twice as intense (e.g. loud, heavy, bright, etc.) as another. It is presupposed that even if these judgments are inaccurate (e.g., if in actuality the given stimulus is three times as intense as the other one), they are intersubjective (shared by all subjects). The general psychophysical law they have advanced has been that equal ratios between stimuli produce equal subjective ratios.

However, these theories are heavily criticized in psychophysics today (Poulton 1989; Anderson 1989, 1992; Laming 1997; see also Wikipedia, the free encyclopedia under "Stevens' power law"), on the basis that the experimental methodology has been problematic and presupposed the power law (Poulton 1989; Laming 1997), and on the basis of empirical findings. Featherstone (to appear) discusses these critics at some length, concluding that people can generally build and use scales that encode differences between measures of stimuli, and sometimes also, but not necessarily, ratios.

\footnotetext{
20 This paper is not addressed to experts in psychophysics, nor am I such an expert. Yet I believe that some reflection on recent developments in this field can be illuminating in the context of this paper. I therefore hope the following discussion succeeds in delivering the main ideas relevant to our purposes.
} 
Featherstone also makes an interesting new case for this claim, based on the experimental research of judgments of linguistic wellformedness. Featherstone shows that more accurate and informative results are obtained when subjects are encouraged to rank differences, rather than ratios, between the wellformedness of different linguistic structures, and when the data is processed accordingly.

Featherstone's new view is in line with my assumption that the degree functions of many positive adjectives do not represent ratios, as they do not have a uniquely determined, agreed upon zero point (either in the first place, or because they are transformed) and that ratio statements are used only when additional information is presupposed (regarding the zero point, or regarding the transformation value being equal to zero). The adjective felicitous forms an example of an adjective for which no zero point exists in the first place, yet differences between degrees accurately describe differences in felicity.

Most plausibly, the majority of positive adjectives denote measures with all the properties of interval-scales in the first place, and sometimes, but not always, also properties of ratio-scales. When subjective judgments or internal states (e.g., degrees to which things feel heavy, loud, warm, tasty, funny, felicitous, nice, happy, organized, etc.) are at stake, the likelihood that speakers will regard the measure as additive (ratio-scale) is, presumably, reduced, but it is not nullified. Speakers may use ratio-statements (or consider them acceptable) to the extent that their beliefs allow for the possibility that ratio measures exist. ${ }^{21}$ While for negative adjectives we have an a priory reason to assume that they do not associate with ratio scales, for any positive adjective (and context) we have to check, case by case, whether we are willing to treat the mapping as ratio-scale or not (cf. my earlier discussion of happy in 3.1).

Notice, however, that we are normally surprised by discoveries of discrepancies between (i) our sensation of stimuli's magnitudes (say, how loud or hot they are felt to be) and (ii) the stimuli's measures on a given 'objective' scale (e.g., a Hertz or Kelvin scale, respectively). This shows that we presuppose that reality resembles the way we perceive or represent it, which, in actuality, is not always the case. Thus, most probably, even if connections between stimuli and their sensation are logarithmic, the connections between stimuli-representations (in the ontology that language users presuppose) and the numerical values assigned to them by speakers (via the degree functions of predicates) are nonetheless simply linear.

In other words, individuals in the domain $\mathrm{D}$ correspond to subjective representations of physical stimuli (and their magnitudes), and degree functions in $\Re^{\mathrm{D}}$ (adjectival interpretations) are either ratio-based or difference-based numerical representations of these subjective magnitude representations. If so, rather than psychophysical findings, linguistic data (felicity judgments and distributional facts) regarding utterances with difference and ratio modifiers (such as 2 degrees hotter, twice as happy, and two inches

\footnotetext{
21 A common practice in the social sciences is to present subjects with a numerical scale while instructing them that the differences between any two adjacent values are identical. If the scale has a zero (representing complete absence of the measured property), data analysis relying on addition and multiplication (averaging, t-test, etc.) is considered appropriate, i.e. subjects are thought of as capable of producing ratio judgments in the given cases.
} 
long) should constitute the main data refuting or supporting linguistic theories such as the present one.

\subsection{Between-predicate comparisons based on a common unit}

The present analysis of unit-names directly captures the conditions under which predicates with conventional unit names can co-occur in between-predicate comparisons, as in (22a-b).

(22) a. The sofa is longer than it is wide.

b. The sofa is $2 \mathrm{~m}$ longer than it is wide.

The set of objects $1 \mathrm{~m}$ long and the set of objects $1 \mathrm{~m}$ wide are different. However, in real life, we use the same rulers for length and width, which means that we assume that the degrees of the (different) unit objects of wide and long are identical for any given measuring system (they are mapped to the same number given an inch ruler, they are mapped to the same number given a meter ruler, etc.). Formally, this means that in every total context $\mathrm{t}$, the (different) unit-objects of wide and long always have the same degree, e.g., the statements in (22) are acceptable because $\forall \mathrm{t} \in \mathrm{T}_{\mathrm{c}}: \mathrm{r}_{\text {meter-long, } \mathrm{t}}$ $=r_{\text {meter-wide, } t}$, i.e., in any $\mathrm{t}, \mathrm{f}_{\text {long, } \mathrm{t}}$ maps meter-long unit objects (entities that are $1 \mathrm{~m}$ long) to the same degree to which $f_{\text {wide, }}$ maps meter-wide unit objects (entities which are $1 \mathrm{~m}$-wide). Thus, if we measure the ratio between the length of an entity and the length of a meter-long unit-object, and we measure the ratio between the width of an entity and the width of a meter-wide unit-object, we can meaningfully compare these numbers, e.g., we can say that the difference between the entity's width and length equals twice the length (or width — it does not matter) of a meter:

$$
\begin{aligned}
& \llbracket \text { The sofa is } 2 \text { meters longer than it is wide } \rrbracket_{c}=1 \text { iff } \\
& \forall \mathrm{t} \in \mathrm{T}_{\mathrm{c}}: \mathrm{f}_{\text {long, } \mathrm{t}}\left(\llbracket \text { The sofa } \rrbracket_{\mathrm{t}}\right)-\mathrm{f}_{\mathrm{wide}, \mathrm{t}}\left(\llbracket \text { The sofa } \rrbracket_{\mathrm{t}}\right)=2 \times \mathrm{r}_{\text {meter, } \mathrm{t}}
\end{aligned}
$$

I propose that it is for this reason that comparisons between these predicates are acceptable. Adjectives whose unit objects' degrees are not conventionally determined to co-vary are not comparable in this sense. For example, \#The sofa is longer than it is heavy is odd because we do not use the same measuring tools and unit names for length and weight, which means that the degrees of no units of heavy and long co-vary. To demonstrate this, let us say that the unit meter is chosen as a basis for comparison:

$$
\begin{aligned}
& \llbracket \text { The sofa is } 2 \text { meters longer than it is heavy } \rrbracket_{c}=1 \text { iff } \\
& \forall \mathrm{t} \in \mathrm{T}_{\mathrm{c}}: \mathrm{f}_{\text {long, } \mathrm{t}}\left(\llbracket \text { The sofa } \rrbracket_{\mathrm{t}}\right)-\mathrm{f}_{\text {heavy, } \mathrm{t}}\left(\llbracket \text { The sofa } \rrbracket_{\mathrm{t}}\right)=2 \times \mathrm{r}_{\text {meter, } \mathrm{t}}
\end{aligned}
$$

The truth condition in (24) is rarely met, as the ratios between (i) degrees of length minus degrees of weight of entities and (ii) degrees of length of meter unit-objects do not co-vary across total contexts. So this statement is virtually never true and, therefore, is infelicitous. ${ }^{22}$ Generally:

\footnotetext{
22 For example, even if the transformation value is zero in c in both long and heavy, consider three entities $\mathrm{d}_{1}, \mathrm{~d}_{2}$ and a meter unit-object $\mathrm{d}_{\mathrm{m}}$ such that:
}

a. $\mathrm{f}_{\text {long }}$ maps $\mathrm{d}_{1}$ and $\mathrm{d}_{\mathrm{m}}$ to 4 and 1 in $\mathrm{t}_{1}$ and to 8 and 2 in $\mathrm{t}_{2}$, 


\section{(25) Between-predicate comparisons based on a common unit's degree:}

Degrees in two predicates $\mathrm{P}$ and $\mathrm{Q}$ with conventional unit names $\mathrm{u}_{\mathrm{p}}$ and $\mathrm{u}_{\mathrm{q}}$, respectively, are comparable in c iff the unit objects' degrees co-vary in $T_{\mathrm{c}}$ : $\forall \mathrm{t}$ $\in \mathrm{T}_{\mathrm{c}}, \operatorname{Tran}_{\mathrm{P}, \mathrm{t}}=\operatorname{Tran}_{\mathrm{Q}, \mathrm{t}} \& \mathrm{r}_{\mathrm{P}, \mathrm{t}}=\sigma\left(\left\{\mathrm{f}_{\mathrm{P}, \mathrm{t}}(\mathrm{d}): \mathrm{d} \in \mathrm{D}_{\mathrm{Up}}\right\}\right)=\mathrm{r}_{\mathrm{Q}, \mathrm{t}}=\sigma\left(\left\{\mathrm{f}_{\mathrm{Q}, \mathrm{t}}(\mathrm{d}): \mathrm{d}\right.\right.$ $\left.\left.\in \mathrm{D}_{\mathrm{Uq}}\right\}\right)$

As most adjective pairs (like heavy and long, happy and long, etc.) do not meet this condition, they do not compare based on a shared unit, ${ }^{23}$ e.g., a metal coin weighing one gram and a sofa whose length is one meter, are both mapped to the number 1 in total contexts $t$ in which $f_{\text {weight }}$ and $f_{\text {long }}$ correspond to measurements in grams and meters, respectively. But in any other total contexts (say, total contexts in which $f_{\text {weight }}$ and $f_{\text {long }}$ correspond to measurements in kilograms and inches, respectively), the values assigned to them no longer co-vary. When a common unit name exists, this situation is avoided, as the common name represents the fact that in every total context $t$ of $T_{c}$ (of any context $c$ ), the degree functions of the two adjectives represent the outcome of measuring with the very same tool, i.e., in every total context $t$ of $T_{c}$ the unit objects of both adjectives are mapped to the same number. ${ }^{24}$

\subsection{Intermediate conclusions}

Part 3 presents compelling arguments in support of my proposal, whereby measurement theory's taxonomy of measures (cf. Part 1) and its conception of unit based

\footnotetext{
Footnote 22 continued

b. $\mathrm{f}_{\text {wide }}$ maps $\mathrm{d}_{2}$ and $\mathrm{d}_{\mathrm{m}}$ to 2 and 1 in $\mathrm{t}_{1}$ and to 4 and 2 in $\mathrm{t}_{2}$, and

c. $\mathrm{f}_{\text {heavy }}$ maps $\mathrm{d}_{2}$ to 3 in $\mathrm{t}_{1}$ and to 9 in $\mathrm{t}_{2}$,
}

The ratio between (i) the difference between $\mathrm{d}_{1}$ 's degree in long and $\mathrm{d}_{2}$ 's degree in wide and (ii) the meter unit-objects' degree in long is the same number in $\mathrm{t}_{1}$ and $\mathrm{t}_{2}$ (because the ratio between $\mathrm{d}_{\mathrm{m}}$ 's degree in long and $\mathrm{d}_{2}$ 's degree in wide co-vary, as $\mathrm{d}_{\mathrm{m}}$ 's degree in long is identical to $\mathrm{d}_{\mathrm{m}}$ 's degree in wide):

$\left(\mathrm{f}_{\text {long, } \mathrm{t} 1}\left(\mathrm{~d}_{1}\right)-\mathrm{f}_{\text {wide, } \mathrm{t} 1}\left(\mathrm{~d}_{2}\right)\right) / \mathrm{f}_{\text {long, } \mathrm{t} 1}\left(\mathrm{~d}_{\mathrm{m}}\right)=(4-2) / 1=\mathbf{2}=\left(\mathrm{f}_{\text {long, } \mathrm{t} 2}\left(\mathrm{~d}_{1}\right)-\mathrm{f}_{\text {wide }, \mathrm{t} 2}\left(\mathrm{~d}_{2}\right)\right) / \mathrm{f}_{\text {long, } \mathrm{t} 2}\left(\mathrm{~d}_{\mathrm{m}}\right)=$ $(8-4) / 2=2$

But the ratio between (i) the difference between $\mathrm{d}_{1}$ 's degree in long and $\mathrm{d}_{2}$ 's degree in heavy and (ii) the meter unit-objects' degree in long is a different number in $\mathrm{t}_{1}$ and $\mathrm{t}_{2}$ (because $\mathrm{d}_{\mathrm{m}}$ 's degree in long and $\mathrm{d}_{2}$ 's degree in heavy do not co-vary):

$\left(\mathrm{f}_{\text {long, } \mathrm{t} 1}\left(\mathrm{~d}_{1}\right)-\mathrm{f}_{\text {heavy, } \mathrm{t} 1}\left(\mathrm{~d}_{2}\right)\right) / \mathrm{f}_{\text {long, } \mathrm{t} 1}\left(\mathrm{~d}_{\mathrm{m}}\right)=(4-3) / 1=\mathbf{1} \neq\left(\mathrm{f}_{\text {long, } \mathrm{t} 2}\left(\mathrm{~d}_{1}\right)-\mathrm{f}_{\text {heavy, } 22}\left(\mathrm{~d}_{2}\right)\right) / \mathrm{f}_{\text {long, } \mathrm{t} 2}\left(\mathrm{~d}_{\mathrm{m}}\right)=$ $(8-9) / 2=-\mathbf{1 / 2}$

Thus, we cannot truthfully assert that this ratio is, e.g., 2, or any other given number.

23 There are additional circumstances in which between-predicate licensed comparisons are not dependent on a common unit; for a discussion, see Bale (2008) and Sassoon (2007).

24 Standard accounts of, e.g., the fact that different predicates are not necessarily comparable (see mainly, Kennedy 1999) rely heavily on the notion of dimension. Yet, it is not clear what a dimension is within these account. Kennedy (1999) assumes that the predicates long, wide and high have the same dimension and are therefore comparable. But, intuitively, length, width and height are different (as Kennedy puts it, they order the entities according to different perpendicular aspects). Also, if long and wide share the dimension, a dimension cannot reduce to a predicate meaning (since obviously, different predicates are assumed to share a dimension) or to the set of constraints on the mapping to degrees (since the degree functions of long and wide may map entities to different degrees). In this case, what constitutes a dimension? The notion of a dimension is clarified in the present proposal. My height and happiness can be viewed as elements of the domain D, just like my legs or hair, s.t. the extent I satisfy the corresponding adjectives reflects the quantity that I possess of these dimensions (Moltmann 2006). So wide and long no longer share a dimension. Nonetheless, their comparability is explained. 
measurements (cf. Part 2) can be applied to linguistics and explain (without assuming new lexical, semantic or syntactic mechanisms for these purposes) a large number of semantic and distributional facts regarding unit names and measure phrases, including facts pertaining to

i Adjectives that have unit names and can combine with them to form measure phrases.

ii Adjectives like happy, that have no unit names as it is impossible to agree on conventional unit objects for them.

iii Adjectives like short that have no unit names as their degree function does not encode ratios, but whose comparatives can be modified by measure phrases combined from, e.g., their positive antonyms and their unit names.

iv Adjectives that compare, by virtue of the fact that identical degrees are assigned to their different unit objects in every total context (e.g., long and wide), and

$\mathrm{v}$ Exceptional unit names, which nonetheless are interpreted by native speakers based on the rule in (10), thus further supporting the view that unit names are productively generated and interpreted based on this rule.

The rest of the paper compares the present proposal with previous accounts, elaborating on its broader implications for the theory of gradability and comparison.

\section{General implications: measurement theory in linguistics}

The linguistic theories of gradability and comparison can be divided into two main approaches, which I call the ordinal-scale analysis and the numerical-scale analysis.

\subsection{The ordinal-scale approach}

The ordinal scale approach entertains the assumption that, generally, grammar does not link gradable predicates to comprehensive numerical degrees, but only to ordinal scales, i.e. sets of degrees that represent the ordering between each two entities, but not the precise distance between them. One characteristic of ordinal theories is a tendency to take the ordering relation between entities (the denotation of comparative predicates) to be conceptually primitive, and the entities' degrees to be derived from them (Sapir 1944; Cresswell 1977; Moltmann 2006). ${ }^{25}$ However, a hallmark of an ordinal approach would be the attempt to reduce the interpretation of comparative morphemes such as more and as merely to ordering relations between individuals or between their ordinal degrees in predicates $\mathrm{P}$, i.e., $>_{\mathrm{P}}$ and $\geq_{\mathrm{P}}$, respectively (rather than interpreting more and as as difference operations).

\footnotetext{
25 Briefly, Cresswell (1977) views degrees as equivalence classes under a primitive (primary, a-priori given) ordering relation (the one denoted by the derived comparative of the given gradable adjective). Vaguenessbased gradability theories view our ability to classify objects in denotations as basic, and ordering relations are derived based on this capacity. Degrees, may not be needed at all. If anything, degrees are viewed as, for instance, measures of sets of delineations (possible boundary specifications for vague predicates P; e.g., an entity is more $P$ than other entities iff it falls under P relative to more delineations; Kamp 1975). Examples of Vagueness-based gradability theories include Lewis (1970, 1979), Mcconnell-Ginet (1973), Kamp (1975), Fein (1975), Klein (1980), Landman (1991), and van Rooij (to appear).
} 
A recent example of precisely this sort of an analysis is Bale (2008). Bale gives an appealing analysis of comparisons statements, including comparisons of entities' degrees in two different predicate. The analysis is appealing in that a uniform interpretation of the comparative morpheme is used both for its occurrences in comparisons such as (26a) and in more indirect comparisons such as (26b).

(26) a. The table is wider than it is tall

b. Dan is more beautiful than John is intelligent

c. The table is two inches longer than it is wide

d. Dan is two inches shorter than Sam

e. There are two more children here than there

A main problem for this analysis, which is in the heart of its ordinal nature, is that the analysis does not extend in any obvious way to statements about degree differences (intervals), such as, for example, (26c-d), as well as the use of more in the nominal domain, as in (26e). In fact, ordinalists in general do not attempt to account for all comparatives in terms of ordinal scales only. What ordinalists try to do is to find out where exactly we need how much numerical structure. I return to this point in Sect. 4.2. At present note only that, as Sects. 3.1 and 3.7 show, a truly uniform analysis of comparison statements with and without a numerical degree modifier (e.g., (26a) and $(26 \mathrm{c}-\mathrm{d})$ ) becomes possible if more is analyzed as denoting a difference operation. ${ }^{26}$ A difference-operation analysis of comparative morphemes is characteristic of the numerical approach, as explained in Sect. 4.2.

Note that even under the view of comparative morphemes like ' $e r$ ' as quantifiers (cf. Heim 2000), the meaning of 'er' must be mediated by a minus operation. On this view, e.g., Dan is taller than Sam is is translated roughly to "er( $\lambda$ n.Dan is tall to at least degree $n, \lambda n$.Sam is tall to at least degree $n$ )" (where $n$ is a degree variable). But if we aspire to obtain a unified analysis of more (or other comparative morphemes), we cannot simply regard 'er(P,Q)' as equivalent to “ $\exists$ n: $Q(n) \wedge \neg P(n)$ ” (cf. Kamp 1975; Klein 1980, etc.), as this will not do for, e.g., (26c-d) (Schwarzschild 2008). Rather, we have to assume that 'er(P,Q)' is equivalent to a statement about a measure of the interval of degrees that are $\mathrm{Q}$ but not $\mathrm{P}, \operatorname{Meas}\left(\left\{\mathrm{n}_{2} \mid \mathrm{Q}\left(\mathrm{n}_{2}\right) \wedge \neg \mathrm{P}\left(\mathrm{n}_{2}\right)\right\}\right)$, where Meas is an additive function from degree intervals to numbers. When no measure phrase explicitly modifies the comparative, the interval is claimed to be greater than zero. Otherwise, the measure phrase should be a proper description of the value of Meas, e.g. Dan is two inches taller than Sam is is true in every $t$ in which Mea assigns the set of degrees that Dan reaches but Sam does not a value that equals two times the degree of an inch unit object. Obviously, for this analysis to work, the value Meas assigns should be identical to the difference between Dan and Sam's degrees in every t, i.e., Meas $\mathrm{t}(\{\mathrm{r} \in \mathfrak{R}$ :

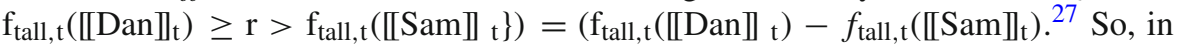
every $\mathrm{t}$, Dan is two inches taller than Sam is is true iff $\left.\mathrm{f}_{\text {tall, } \mathrm{t}}\left(\llbracket \mathrm{Dan} \rrbracket_{\mathrm{t}}\right)-\mathrm{f}_{\mathrm{tall}, \mathrm{t}}\left(\llbracket \mathrm{Sam} \rrbracket_{\mathrm{t}}\right\}\right)$ $=2 \times \mathrm{r}_{\mathrm{i}, \mathrm{t}}$.

\footnotetext{
${ }^{26}$ For reasons of space, I do not deal with indirect comparisons, e.g., (26b) here, but see Sassoon (2007).

27 To see this, imagine that Dan is 2 inches taller than Sam, who is 2 inches taller than Lyn, who is 66 inches tall. Mea's degrees must represent the fact that the difference between Dan and Lyn is twice the difference between Dan and Sam, which equals the difference between Sam and Lyn, which is 1/33 times Lyn's height, etc.
} 


\subsection{The numerical approach}

The numerical approach characterizes gradable adjectives as associated with 'numerical' degree functions, i.e. mapping of entities $\mathrm{d} \in \mathrm{D}$ to a dense set of degrees, isomorphic or identical to the real numbers $r \in \Re$ (Kennedy 1999). In particular, theories in this approach tend to assume that gradable predicates map arguments to degrees for which a plus, difference and ratio operations are applicable (cf., von Stechow 1984a,b). The numerical approach is prevalent in the literature, ${ }^{28}$ as it provides straightforward semantic accounts of expressions whose interpretation is mediated by the application of operations on numbers (identity, multiplication, difference, etc.), such as, e.g., numerical degree predicates, like 2 meters tall, ratio predicates, like twice as happy as Sam, and difference predicates, like 2 meters shorter than Sam (von Stechow 1984a). Yet, a crucial deficiency of this approach hinges on the notion of additive degree functions.

Additivity ensures that, for example, any n equally tall entities will be mapped to the same number, and their concatenation will be mapped to $\mathrm{n}$ times that number. Thus, additivity implies that the adjective's degree function is a ratio-scale measure. In perusing the assumption of additivity, Klein (1991) uses adjectives such as long and tall as his prime examples, and he does not explicitly characterize a subclass of gradable adjectives to which this assumption should be confined. This fact attracts criticism (cf., Moltmann 2006; Kamp and Partee 1995). In particular, versions of the numerical approach, on which the set of adjectives whose interpretation is additive is not appropriately restricted, have to explain the highly restricted distributions of ratio modifiers, unit names and measure phrases by relying on special assumptions, which are often highly stipulative. ${ }^{29}$ In this paper, I have addressed precisely this problem, providing a variety of compelling reasons to classify certain adjectives, but not others, as capable of denoting ratio-scale properties, and certain adjectives, but not others, as ones for which conventions about units can be established.

More generally, for ordinalists, the numerical approach stipulates numerical structure too often, even where that is unnecessary. In the present proposal, cases in which we do not use mappings to numbers are represented as cases in which though total extensions of actual (partial) contexts specify mappings to numbers, and differences and ratios between numbers, actual contexts do not. Formally, too many kinds of mappings are possible (a standard way of representing lack of information). In this

\footnotetext{
28 See Russell (1905), Bartsch and Venneman (1972), Klein (1991), von Stechow (1984a), Kamp and Partee (1995), Kennedy (1999), Heim (2000), Schwarzschild and Wilkinson (2002), Landman (2005).

29 For example, some researchers explain the limited distribution of measure phrases by stating that some (but not all) adjectives are ambiguous. Except for their standard interpretation, ambiguous adjectives have an additional special type of interpretation (e.g. the 'dimensional measure interpretation' in Landman 2005, and the 'interval' interpretation in Schwarzschild 2005). According to these theories, the licensing of numerical degree modifiers depends on the existence of this additional interpretation. Relying on ambiguity, this type of accounts is less economic. In addition, it fails to identify any relevant characteristic of scales of positive adjectives that do not license measure phrases, as opposed to ones that do. Similarly, Svenonious and Kennedy (2006) postulate that in numerical degree constructions a null head Meas ${ }^{o}$ selects for adjectives of a particular type. While these theories may be descriptively adequate, the present paper provides a more explanatory account, because it elucidates the limited distribution of unit names and measure phrases based on the nature of their interpretation.
} 
way, my proposal does capture cases in which no specific numerical structures are actually ever used. At the same time it provides unified semantic analyses for morphemes like twice and $e r$ in terms of numerical operations.

\section{Conclusions}

This paper shows that there is more in measurement theory than semanticists commonly use. The distinctions between ratio, interval, ordinal and nominal scales provide the right constraints on the distribution of expressions in natural languages, whose interpretation is mediated by mathematical operations, such as difference-modifiers, ratio-modifiers, unit names and measure phrases. Also, a main difference between measurement theory as such (as it is usually used by ordinalists) and my own use of it is that I embed it in a model representing partial information about measures. In actuality we can represent any ordering structure by infinitely many types of mappings; it follows that when we speak of "the mapping to numbers" (or "degree function") of an adjective we cannot tell which mapping it is. There are many possibilities. In Table 3, I summarize the distinctions between predicates that I classify as ratio, interval and ordinal, based on the type of information that the values of their degree function encode. A variety of examples are given in Table $4 .^{30}$

Table 3 Linguistic contrasts corresponding to the type of information encoded by the degree functions of different predicate types

\begin{tabular}{|c|c|c|}
\hline Ratio & Interval & Ordinal \\
\hline Information about ratios: & No information about ratios: & $\begin{array}{l}\text { No information } \\
\text { about ratios: }\end{array}$ \\
\hline Dan is twice as tall as Sam & \#Dan is twice as short as Sam & $\begin{array}{l}\text { \#Tweety is twice as a bird as } \\
\quad \text { Tan }\end{array}$ \\
\hline Dan is twice as happy as Sam & \# Dan is twice as unhappy ... & $\begin{array}{l}\text { \#...twice as "bald and tall" } \\
\text { as Tan (where twice takes } \\
\text { scope over and) }\end{array}$ \\
\hline Information about intervals: & Information about intervals: & $\begin{array}{l}\text { No information about } \\
\text { intervals: }\end{array}$ \\
\hline Dan is 2 inches taller than Sam & $\begin{array}{l}\text { Dan is } 2 \text { inches shorter than } \\
\quad . .\end{array}$ & $\begin{array}{l}\text { \#Tweety is more a bird than } \\
\text { Tan }\end{array}$ \\
\hline Information about ordering: & Information about ordering: & Information about ordering: \\
\hline $\begin{array}{l}\text { Dan's degree (the extent it } \\
\text { satisfies the property) 'tall' } \\
\text { is bigger than Sam's }\end{array}$ & $\begin{array}{l}\text { Dan's degree in (the extent it } \\
\text { satisfies the property) } \\
\text { 'short' is bigger than Sam's }\end{array}$ & $\begin{array}{l}\text { Tweety's degree in (the extent } \\
\text { it satisfies the property) } \\
\text { 'bird' is bigger than Tan's }\end{array}$ \\
\hline
\end{tabular}

\footnotetext{
30 About 'ordinal' examples see (Sassoon 2007, Chap. 9); See Murphy (2002) for an extensive review of empirical findings showing that speakers have firm, gradable judgments of goodness of examples in nominal categories, e.g., robins are considered better examples of birds than ostriches or penguins, and the goodness of an example determines its likelihood of classification as a bird.
} 
Table 4 Examples of the different predicate types

\begin{tabular}{|c|c|c|}
\hline Ratio & Interval & Ordinal / Nominal \\
\hline $\begin{array}{l}\text { Many measures of physical } \\
\text { quantities, such as length }\end{array}$ & Negated predicates & Binary adjectives \\
\hline Measures of age & Negative predicates (short) & Nouns and noun phrases \\
\hline Length of residence in a place & $\begin{array}{l}\text { Positive predicates in which } \\
\text { intuitions about the zero } \\
\text { point are blurred (warm) }\end{array}$ & Conjunctions, Disjunctions \\
\hline Comparatives & & $\begin{array}{l}\text { Conjunctive or disjunctive } \\
\text { adjectives (healthy wrt } \\
\text { blood pressure, pulse and } \\
\text { body fever) }\end{array}$ \\
\hline $\begin{array}{l}\text { Tall, long, wide, big, weighs, } \\
\text { happy, cold } \text { mental }^{\text {a }}\end{array}$ & $\begin{array}{l}\text { Cold temperature, warm, heavy, } \\
\text { short, small, light }\end{array}$ & $\begin{array}{l}\text { Prime, bird, apple, tall person, } \\
\text { fat or bald, fat and happy }\end{array}$ \\
\hline
\end{tabular}

\begin{abstract}
Aknowledgments This work was made possible by the Orgler Scholarship, Tel Aviv University (20042007), and the Pratt postdoc scholarship, Ben Gurion University of the Negev (2007-2008). Part of the research for this paper was carried out in the project 'On vagueness - and how to be precise enough', funded by the Netherlands Organization for Scientific Research (NWO 360-20-201). I warmly thank my former supervisors Nirit Kadmon and Fred Landman. I also wish to thank personally Robert van Rooij and Danny Fox for invaluable comments on drafts of this paper. This paper is based on my conference presentation in "Vagueness and Language use", April 2008, Paris, and my presentations in SUB13, and IATL24. I warmly thank the reviewers and audience of these conferences, as well as those of SALT XVIII, for their most helpful comments. Special thanks to Arik Cohen, Arnim von Stechow, Manfred Krifka, Edit Doron, Roger Schwarzschild, Sally McConnell Ginet, Chris Kennedy, Louise McNally, Yael Sharvit, Micha Breakstone and Adar Weidman. Needless to say, any mistakes are solely mine.
\end{abstract}

Open Access This article is distributed under the terms of the Creative Commons Attribution Noncommercial License which permits any noncommercial use, distribution, and reproduction in any medium, provided the original author(s) and source are credited.

\title{
References
}

Anderson, N. (1989). Integration psychophysics. Behavioral Brains Science, 12, 268-269.

Anderson, N. (1992). Integration psychophysics and cognition. In D. Algom (Ed.), Psychophysical approaches to cognition (pp. 13-113). Amsterdam: North Holland.

Anderson, N. (1996). A functional theory of cognition. Hillsdale, NJ: Lawrence Erlbaum Associates.

Babbie, E. (2004). The practice of social research (10th ed.). Wadsworth: Wadsworth Thomson Learning Inc.

Bale, A. C. (2008). A universal scale of comparison. Linguistics and Philosophy, 31(1), 1-55.

Bartsch, R., \& Venneman, T. (1972). Semantic structures (pp. 47-86). Frankfurt: Anthenäum Verlag.

Bierwisch, M. (1989). The semantics of gradation. In M. Bierwisch \& E. Lang (Eds.), Dimensional adjectives: Grammatical structure and conceptual interpretation (pp. 71-261). Berlin: SpringerVerlag.

Brasoveanu, A. (2008). Measure noun polisemy and monotonicity: Evidence from Romanian pseudopartitives. In Proceedings of the 38th meeting of the north east linguistic society.

Chierchia, G. (1998). Plurality of mass nouns and the notion of semantic parameter. In S. Rothstein (Ed.), Events and grammar (pp. 53-103). Dordrecht: Kluwer.

Cresswell, M. J. (1977). The semantics of degree. In B. Partee (Ed.), Montague grammar (pp. 261292). New York: Academic Press.

Featherston, S. (to appear). Why linguistics need boiling and freezing points. To appear in: Fruits: The productive application of evidence to linguistic problems. Berlin: de Gruyter. 
Fein, K. (1975). Truth, vagueness and logics. Synthese, 30, 265-300.

Heim, I. (2000). Degree operators and scope. Proceedings of SALT X. Ithaca, NY: CLC Publications.

Horn, L. (1972). On the semantic properties of logical operators in English. Unpublished doctoral dissertation, University of California, Los Angeles.

Kamp, H. (1975). Two theories about adjectives. In E. Keenan (Ed.), Formal semantics for natural language (pp. 123-155). Cambridge: Cambridge University Press.

Kamp, H., \& Partee, B. (1995). Prototype theory and compositionality. Cognition, 57, 129-191.

Kennedy, C. (1999). Projecting the adjective: The syntax and semantics of gradability and comparison. New York: Garland (1997 UCSC Doctoral dissertation).

Kennedy, C. (2001). Polar opposition and the ontology of degrees. Linguistics and Philosophy, 24(1), 33-70.

Kennedy, C., \& Levin, B. (2007). Measure of change: The adjectival core of degree achievements. In L. McNally \& C. Kennedy (Ed.), Adjectives and adverbs: Syntax, semantics and discourse. Oxford: Oxford University Press.

Kennedy, C., \& McNally, L. (2005). Scale structure and the semantic typology of gradable predicates. Language, 81, 345-381.

Klein, E. (1980). A semantics for positive and comparative adjectives. Linguistics and Philosophy, 4, 1-45.

Klein, E. (1991). Comparatives. In A. von Stechow \& D. Wunderlich (Eds.), Semantik/semantics, an international handbook of contemporary research (pp. 673-691). Berlin, NY: Walter de Gruyter.

Krantz, D. H., Luce, R. D., Suppes, P., \& Tversky, A. (1971). Foundations of measurement: Additive and polynomial representations. San Diego, London: Academic Press, University of Fribourg.

Krasikova, S. (2009). Norm-relatedness in degree constructions. In A. Riester \& T. Solstad (Eds.), Proceedings of Sinn und Bedeutung (Vol. 13). Stuttgart.

Krifka, M. (1989). Nominal reference, temporal constitution and quantification in event semantics. In R. Bartsch, van J. Benthem, \& van P. Emde Boas (Eds.), Semantics and contextual expressions (pp. 75-115). Dordrecht: Foris.

Laming, D. (1997). The measurement of sensation. Oxford: Oxford University Press.

Landman, F. (1991). Structures for semantics. Dordrecht: Kluwer.

Landman, F. (2005). An almost (but not quite) naïve theory of measures, manuscript, Tel Aviv University.

Lewis, D. K. (1970). General semantics. Synthese, 22, 18-67. Reprinted In D. K. Lewis (1983). Philosophical Papers, 1, 189-229. New York: Oxford University Press.

Lewis, D. K. (1979). Scorekeeping in a language game. Journal of Philosophical Logic, 8, 339-359. (Reprinted In Philosophical Papers, 1, pp. 233-249, by D. K. Lewis, Ed., 1983, New York: Oxford University Press.

Mcconnell-Ginet, S. (1973). Comparative constructions in English: A syntactic and semantic analysis. A Doctoral dissertation, University of Rochester.

Moltmann, F. (2006). Comparatives without degrees. A new approach. A manuscript for the workshop on scalar meaning, University of Chicago.

Murphy, G. (2002). The big book of concepts. Cambridge, MA: The MIT Press.

Murphy, M. L. (2006). Semantic, pragmatic, and lexical aspects of the measure phrase + adjective construction. In M.-B. Mosegaard Hansen \& K. Turner (Eds.), Acta lingvistica hafniensia 38.

Poulton, E. C. (1989). Bias in quantifying judgments. Hove and London: Erlbaum.

Rett, J. (2007). Antonymy and evaluativity. In Proceedings of semantics and linguistic theory, Vol. 17. University of Connecticut, CLC Publications.

Russell, B. (1905). On denoting. Mind, 14, 479-493 (Reprinted from Essays in Analysis, pp. 103-119, by Russell, B., 1973, London: Allen and Unwin).

Sapir, E. (1944). Grading: A study in semantics. Philosophy of Science, 11, 93-116.

Sassoon, W. G. (2007). Vagueness, gradability and typicality, a comprehensive semantic analysis. Unpublished doctoral Dissertation, Tel Aviv University.

Sassoon, W. G. (2009). The degree functions of negative adjectives. Manuscript.

Schwarzschild, R. (2005). Measure phrases as modifiers of adjectives. Recherches Linguistiques de Vincennes, 35, 207-228.

Schwarzschild, R. (2006). The role of dimensions in the syntax of noun phrases. Syntax, 9(1), 67-110.

Schwarzschild, R. (2008). The semantics of comparatives and other degree constructions. Language and Linguistics Compass, 2.2, 308-331.

Schwarzschild, R., \& Wilkinson, K. (2002). Quantifiers in comparatives: A semantics of degree based on intervals. Natural Language Semantics, 10, 1-41. 
Seuren, P. (1978). The structure and selection of positive and negative gradable adjectives. In Papers from the Para-session on the Lexicon. 14th Regional Meeting of the Chicago Linguistic Society (pp. 336-346). CLS, Chicago, IL.

Stalnaker, R. (1978). Assertion. In P. Cole, Syntax and semantics 9: Pragmatics (pp. 315-332). New York: Academic Press.

Stevens, S. S. (1946). On the theory of scales of measurement. Science, 103, 677-680.

Stevens, S. S. (1957). On the psychophysical law. Psychological Review, 64(3), 153-181.

Stevens, S. S. (1975). Psychophysics. New York: Wiley.

Svenonious, P., \& Kennedy, C. (2006). Northern Norwegian degree questions and the syntax of measurement. In M. Frascarelli, Phases of interpretation (pp. 133-161). The Hague: Muton de Gruyter.

van Fraassen, B. C. (1969). Presuppositions, supervaluations and free logic. In K. Lambert, The logical way of doing things (pp. 67-91). New Haven: Yale University Press.

van Rooij, R. (to appear). Vagueness and linguistics. In G. Ronzitti (Ed.), The vagueness handbook. Dordrecht: Springer.

Veltman, F. (1984). Data semantics. In J. Groenendijk, T. Janssen \& M. Stokhof (Eds.), Truth, interpretation and information proceedings of the 3rd Amsterdam colloquium.

von Stechow, A. (1984a). My reaction to Cresswell's, Hellan's, Hoeksema's and Seuren's comments. Journal of Semantics, 3, 183-199.

von Stechow, A. (1984b). Comparing semantic theories of comparison. Journal of Semantics, 3, 1-77. 